\title{
Terrain-driven unstructured mesh development through semi-automatic vertical feature extraction
}

\author{
Matthew V. Bilskie, ${ }^{\mathrm{a}, *}$, David Coggin ${ }^{\mathrm{b}}$, Scott C. Hagen ${ }^{\mathrm{a}, \mathrm{c}}$, Stephen C. \\ Medeiros $^{\mathrm{d}}$ \\ ${ }^{a}$ Department of Civil and Environmental Engineering, Louisiana State University, Baton \\ Rouge, Louisiana \\ ${ }^{b}$ Marea Technology, Green Cove Springs, FL \\ ${ }^{c}$ Center for Computation and Technology, Louisiana State University, Baton Rouge, \\ Louisiana \\ ${ }^{d}$ Department of Civil, Environmental, and Construction Engineering, University of \\ Central Florida, Orlando, Florida
}

\begin{abstract}
A semi-automated vertical feature terrain extraction algorithm is described and applied to a two-dimensional, depth-integrated, shallow water equation inundation model. The extracted features describe what are commonly sub-mesh scale elevation details (ridge and valleys), which may be ignored in standard practice because adequate mesh resolution cannot be afforded. The extraction algorithm is semi-automated, requires minimal human intervention, and is reproducible. A lidar-derived Digital Elevation Model (DEM) of coastal Mississippi and Alabama serves as the source data for the vertical feature extraction. Unstructured mesh nodes and element edges are aligned to the vertical features and an interpolation algorithm aimed at minimizing topographic elevation error assigns elevations to mesh nodes via the DEM. The end result is a mesh that accurately represents the
\end{abstract}

\footnotetext{
${ }^{*}$ Corresponding Author

Email address: Matt.Bilskie@gmail.com (Matthew V. Bilskie)
}

Preprint submitted to Adv. Water Res.

September 22, 2015 
bare earth surface as derived from lidar with element resolution in the floodplain ranging from $15 \mathrm{~m}$ to $200 \mathrm{~m}$. To examine the influence of the inclusion of vertical features on overland flooding, two additional meshes were developed, one without crest elevations of the features and another with vertical features withheld. All three meshes were incorporated into a SWAN+ADCIRC model simulation of Hurricane Katrina. Each of the three models resulted in similar validation statistics when compared to observed time-series water levels at gages and post-storm collected high water marks. Simulated water level peaks yielded an $R^{2}$ of 0.97 and upper and lower $95 \%$ confidence interval of $\sim \pm 0.60 \mathrm{~m}$. From the validation at the gages and HWM locations, it was not clear which of the three model experiments performed best in terms of accuracy. Examination of inundation extent among the three model results were compared to debris lines derived from NOAA post-event aerial imagery, and the mesh including vertical features showed higher accuracy. The comparison of model results to debris lines demonstrates that additional validation techniques are necessary for state-of-the-art flood inundation models. In addition, the semi-automated, unstructured mesh generation process presented herein increases the overall accuracy of simulated storm surge across the floodplain without reliance on hand digitization or sacrificing computational cost.

Keywords: Vertical Features, Shallow Water Equations, Unstructured Mesh, Hurricane Katrina, Storm Surge, Hydrodynamics, Validation 


\section{Introduction}

Physics-based, two-dimensional, unstructured mesh flood inundation models governed by forms of the Navier-Stokes equations are used to study historic flooding events and assess future flooding scenarios. Enhanced knowledge of overland flow physics, improved data collection methods, and superior scientific computing technology have resulted in a transition from structured grids to unstructured mesh models [1] 6 . An unstructured triangular mesh is the medium for which a continuous domain (e.g., Earth's surface) can be discretized, and is composed of non-overlapping elements (or cells) connected by mesh nodes (element vertices). Unstructured elements are attractive due to their ability to conform and adapt to local geometry. The capacity to increase resolution in regions of large topographic variability, high solution gradients, and areas of interest also enhance the appeal of unstructured elements [7-9].

FEMA (Federal Emergency Management Agency) has adopted an unstructured mesh framework for the development of digital flood insurance rate maps (DFIRM) along the U.S. coastline [10, 11]. These models are used as a basis to evaluate restoration and protection strategies for coastal Louisiana [12] and provide real-time forecasts of hurricane waves and storm surge for the U.S. east coast and northwestern Gulf of Mexico that aid evacuation management and planning [13]. Additionally, variations of these unstructured mesh models are now being used to estimate potential flood risk under future global climate change scenarios and sea level rise (SLR) [14-18] as well as biological assessments of inter-tidal salt marshes [19].

The overarching goal when designing an unstructured mesh is to accu- 
rately represent the natural system while maintaining a given computational cost [7]. The density and topology of computational points (mesh nodes) and the alignment of element faces across the floodplain must be critically examined. To reduce computer run times and increase the usability of the models, unstructured meshes are restricted to a minimum element size. This element size limitation induces numerous discretization errors such as the variances of the planar triangular elements from the true surface (mesh elevation error). If mesh node density is too coarse or nodes are not appropriately placed, important hydraulic terrain features may be smoothed-out, particularly in the floodplain, and lead to inaccurate model results [20]. The floodplain introduces a high order of non-linearity due to higher spatial variability in both topography and drag forces. This results in steeper solution gradients than those found in consistently wetted areas (i.e., ocean basins, rivers, lakes, etc.). Additionally, the floodplain may contain anthropogenic features that do not belong to the bare earth surface from which inundation model elevations are derived. However, these man-made features are included as part of the Earth's surface as they are (relatively) impervious with respect to inundation [20, 21].

Increasing model resolution within the floodplain may permit an enhanced representation of the bare earth topography; however, sub-mesh scale features (referred to as vertical features herein) exist that are not properly described by unstructured elements without additional treatment. Some of these features are obvious (e.g., levees and raised roadbeds) and are included in standard digitization practices. However, other features may escape visual recognition or are not included because they are too narrow to be discretized 
2 features can impact the path, pattern, duration, and magnitude of overland 3 flooding, as well as modify flooding frequency [21, 22].

4 It is crucial that vertical features be appropriately and accurately in5 cluded in inundation models, especially in urban regions where flood risk can 6 drastically change with minor differences in inundation extent [20]. Bates et 7 al. 23] employed an $18 \mathrm{~m}$ lidar-derived digital elevation model (DEM) to 8 simulate flooding in the River Severn using the LISFLOOD-FP raster-based

two-dimensional inundation model. Key topographic features such as embankments and flood walls were found to be smoothed by the coarse DEM. These key features were identified from the UK Ordnance Survey Landline vector data and their elevation was sustained at the model scale. Purvis et al. 24] hand digitized significant terrain features from UK Ordnance Survey maps and their crest elevations obtained from lidar data were added back into a $50 \mathrm{~m}$ DEM for use in a LISFLOOD-FP inundation model along the UK coast in Somerset, South-West England. Schubert et al. [20] developed a semi-automated method to use MasterMap ${ }^{\circledR}$ geospatial data to guide unstructured mesh generation to model flooding in Glasgow, Scotland using the BreZo shallow-water flow model. The mesh generation software Triangle [25] was used to align mesh vertices and element edges to terrain features, keeping hydraulic connectivity within the mesh. Gallien et al. 26] aligned mesh nodes to topographic features prone to overtopping. Polylines of the terrain features that were used in mesh generation were obtained from real time kinematic (RTK) surveys and orthoimagery. Experiments were performed using the BreZo model for four different meshes with vertex elevations derived from 
the lidar DEM, RTK surveyed elevations in addition to the uncertainty in RTK and lidar elevations. It was shown that accurate flooding depths can be obtained if hydraulic features are accurately surveyed and included in the inundation model. Hurricane storm surge models of southeastern Louisiana using ADCIRC [27] have included levee systems, interstate and state highways, and railroads that are raised above the neighboring topography and are defined as weirs by their respective crown heights. However, the weir boundary condition in ADCIRC does not allow for wave overtopping and indirectly increases node count as each weir mesh node must have a neighboring pair [28, 29].

These studies highlight the necessity of including hydraulic connectivity in inundation models and methods for which to do so. However, the scales at which some state-of-the-art river reach and coastal inundation models are constructed, often spanning large geographic regions, discourage manual digitization of vertical features for inclusion in these models. Additionally, public or private data containing man-made hydraulic features are not always available, are outdated and require manual digitization, or require traditional land surveying [30]. This creates an opportunity for the development and application of an automated feature extraction algorithm to guide floodplain unstructured mesh generation, which is a major objective of this paper.

Methods for extracting geomorphic features from DEMs is not a new problem (see Table 1 for a general summary). However, establishing automated methods is not straightforward [30]. Low-relief landscapes are particularly challenging due to their low topographic gradient and anthropogenically influenced landscape and channel networks [31. There have been a number 
1 of attempts to extract river and channel networks from DEMs and high 2 resolution lidar data, including flow direction and curvature based methods 3 [31 37]. Passalacqua et al. [31] extended the ability of GeoNet to automate 4 the extraction of channel heads and networks using dense lidar data in a flat 5 and human-impacted region. Mason et al. [36] developed a semi-automated 6 method to extract tidal channel networks from lidar data in Venice Lagoon 7 that was superior to standard methods of river network extraction when applied to tidal channels.

Similarly, several methods have been proposed to extract ridge features from DEMs, and in general are concentrated on extracting breaklines and watershed boundaries. Early work in ridge feature extraction was done by comparing a point's elevation relative to its surrounding points or neighbors [32, 38 40]. Briese [41] and Brzank [42] used shape fitting methods to extract breaklines from lidar data by using geometric objects with shapes that roughly match the desired terrain elements. Contour line methods mimic human methods of feature extraction by locating points of maximum curvature and connecting them as ridges or ravines [43]. However, these methods pose several issues when using contour lines derived from lidar. For example, they may miss features such as highways with flat tops or slight grade [44]. Watershed delineation techniques [45-47] are promising for ridge feature extraction because a watershed boundary satisfies the intuitive definition of a ridge; water on the ridge will fall downhill in opposite directions.

Automated techniques for detecting anthropogenic ridge features from lidar have been proposed, particularly for levee systems, dikes, and roadways [22, 48, 49]. Several studies have applied image analysis techniques for feature 
extraction that mainly focus on edge detection [50, 51, 44, 52. However, these methods generally do not precisely detect ridges in a geomorphologic sense (i.e., declare ridges based on water flowing down-gradient).

These approaches are not focused on terrain extraction with respect to generating a well conforming unstructured finite element mesh to model shallow water hydrodynamics. Therefore, this work addresses a significant lack in published literature dealing with unstructured mesh generation across lowgradient landscapes. Since the primary concern is an accurate computation of inundation area, the overland portion of the mesh must accurately capture raised features such as road beds, topographic ridge lines and valleys that serve to limit and route overland flow. Additionally, the geographic placement of computational points must be accompanied by an accurate topographic elevation.

In this paper, we present a reproducible and novel semi-automated method to extract vertical features (ridges and valleys) from a lidar DEM for use in the development of flood inundation models. The semi-automated methods presented are not fully standalone and require data processing steps coupled with manual intervention. These enhancements improve the description of sub-grid scale features (horizontal and vertical alignment) and the overall accuracy of floodplain elevations in the model. We employ methods to describe the overland terrain as accurately as possible, with mesh building criteria based on local element size that aim to quantify and minimize topographic elevation error. The goal is to present a semi-automated mesh generation method that can be employed to generate topographically accurate unstructured meshes for shallow water hydrodynamics across any geographic region. 
We begin with a description of the methods used to generate a lidarderived DEM for the coastal Mississippi and Alabama floodplains (Figure 1) and continue with the presentation of the semi-automated vertical feature extraction algorithm. Next, the generation of three unstructured finite element meshes are discussed and each are employed in a Hurricane Katrina storm surge simulation. Results of each simulation are compared against time-series water levels and high water marks in addition to debris lines in post-storm aerial photography.

\section{Materials and Methods}

\subsection{Inundation Model}

Hydrodynamics are simulated using the SWAN+ADCIRC model framework. ADCIRC solves the 2D shallow-water equations for water levels and depth-integrated currents [29, 27, 53]. SWAN, a third-generation wave model, solves for relative frequency and wave direction using the action balance equation for wave-current interactions [54, 55]. The SWAN and ADCIRC models are coupled to run on the same unstructured mesh, removing the need for interpolation between model grids [56, 57]. The ADCIRC timestep is $1 \mathrm{~s}$ and the SWAN timestep is $600 \mathrm{~s}$. Every $600 \mathrm{~s}$ (in alignment with the SWAN timestep), ADCIRC passes water levels and currents to SWAN and SWAN passes wave radiation stress gradients back to ADCIRC. Wave frequencies in SWAN are discretized into 40 bins (log scale) spanning the frequency range of 0.031384 to $1.420416 \mathrm{~Hz}$ and wave directions are discretized into 36 equal interval bins of $10^{\circ}$ [1]. Parameters employed in SWAN include wave growth due to wind based on Komen et al. [58] and Cavaleri et al. [59] and the 
modified whitecapping formulation of Rogers et al. [60]. Depth-induced wave breaking in shallow water is computed via Battjes et al. [61] with the maximum wave height over depth (wave breaking index) $\gamma=0.73$. Bottom friction is tightly coupled with ADCIRC, where Manning's $n$ is applied via Madsen et al. 62] to compute roughness length at each mesh node for each time step. Convergence must be met at $95 \%$ of the grid points and the maximum number of iterations per SWAN time step is limited to 20. Also note that SWAN limits the spectral propagation velocities to deter false wave refraction in regions of inadequate mesh resolution 63]. These parameters are similar to those employed in recent SWAN+ADCIRC models of similar geographic scale and mesh resolution in Louisiana and Texas [1, 64].

\subsection{Unstructured mesh generation}

Generation of an unstructured finite element mesh includes several phases, beginning with a representation of the bare earth land elevation, the most important factor in gravity-driven hydrodynamics [65] (Figure 22). The lidarderived digital elevation model (DEM) is the source dataset by which local node density is determined (mesh size distribution function) and drives the semi-automated vertical feature extraction. The outer model boundary coupled with internal constraints (vertical features) guide the unstructured mesh triangulation in the interior of the domain. Elevations for each mesh node are then interpolated from the original lidar-derived DEM. A detailed description of these methods are discussed in the following sections. 


\subsection{Digital elevation model}

A lidar-derived DEM for Baldwin and Mobile Counties, Alabama, and Jackson, Harrison, and Hancock Counties, Mississippi from the shoreline (0 m elevation contour, NAVD88 [North American Vertical Datum of 1988]) to the $15 \mathrm{~m}$ (NAVD88) contour was developed to represent present-day conditions. In all, two DEMs were constructed (overland and water) and merged to create a seamless topographic/bathymetric (topobathy) DEM.

The Terrain Data Set (TDS) framework within ArcGIS 10.0 was utilized to generate the topographic DEM [66]. A TDS was created for each county using the most recent and available source data: lidar, hydrographic breaklines, and hand-digitized shorelines based on satellite aerial imagery. Specifics about the lidar sources can be found in Bilskie et al. [67, 3]. A $5 \mathrm{~m}$ DEM from each county's TDS was created using natural neighbor interpolation and then combined (mosaic). A $5 \mathrm{~m}$ DEM is sufficient when modeling the terrain in coastal Mississippi for hurricane storm surge applications [67].

A similar TDS framework was utilized for creating a bathymetric DEM. Sources of bathymetry are NOS (National Ocean Service) hydrographic surveys, USACE (U.S. Army Corps of Engineers) channel surveys, NOAA (National Oceanographic and Atmospheric Administration) nautical charts, and previous finite element meshes. The topographic and bathymetric DEMs were merged at the shoreline to create a seamless source elevation dataset.

\subsection{Vertical feature extraction}

Including significant terrain features in the mesh involves two main steps: locating the features and mapping the features to the finite element mesh in a manner that preserves element quality. The method described here 
1 for locating ridge or valley lines (ridges and valleys herein refer to natural 2 or man-made features) begins by extracting watershed boundary lines in a manner that preserves element quality. Points along the watershed boundary 4 lines are then examined relative to the surrounding terrain to determine what 5 portions of the watershed lines represent significant features. Features chosen 6 for inclusion are converted from high-resolution feature lines extracted at the DEM resolution to edges suitable for assembly in the mesh by redistributing s vertices in the feature lines. The redistribution of vertices conforms to the 9 element size available from a two-dimensional size function that provides desired element size as a function of geographic position. Once included in the mesh, the crest of each feature is represented by one or more element edges whose nodes are assigned the crest elevations.

For a natural or man-made feature to merit purposeful inclusion in the model, it must possess three traits: (1) be long enough and (2) high enough to form a significant barrier to local surge propagation; (3) be narrow enough so that careless placement of triangular mesh elements would cause a significant elevation error. The final criterion is needed because of the inability of a discretized mesh to represent features with length scales smaller than the local element size. Such features are often described as sub-grid scale; a common example of a feature that in general meets these three metrics is a raised road bed. Road beds are often long enough and high enough to affect surge propagation, and, depending on the local element size, they are often narrow enough to permit a triangular finite element to overlay the feature with nodes positioned only on the surrounding lower terrain.

The methods for detecting and including raised features in an unstruc- 
tured mesh generally follow and expand upon the procedures originally described in Coggin for the Tampa Bay region [68] and ideas from Roberts [69]. The pseudo-code for the main vertical feature extraction algorithm is presented in Figure 3 and the minimum extraction parameters are shown in Table 2. The algorithm and parameters used rely upon past experience employing the methods in large overland meshes. They have been well tested and adopted by FEMA along the entire Florida Panhandle and Alabama coasts for the development of digital flood insurance rate maps [68, 11, 70].

The feature extraction process is initialized by extracting boundary lines for very small area watersheds. The assumption is that significant barriers to surge propagation will be captured as watershed boundaries. A parameter driven examination of the watershed boundary lines and DEM is then completed, relating the elevation at each point in the boundary lines to the surrounding area in the DEM. The objective is to extract portions of the watershed boundaries that define vertical feature crests meeting the length (long enough), relative elevation (high enough), and steepness or vertical curvature (narrow enough) criteria discussed above. The subjective length, relative elevation, and vertical curvature criteria are converted to objective metrics by defining several measurable parameters and setting required minimum values. The process for evaluating each criterion will be discussed in the order in which they are considered during the extraction process: elevation, vertical curvature, and length.

\subsubsection{Elevation parameters}

Watershed boundaries were extracted from the DEM as discrete lines formed by the vertices in the DEM cells. Each watershed boundary line ver- 
tex was initially assigned a significant, continue, or insignificant attribute by comparing the elevation at its DEM location to elevations at locations generally perpendicular to the direction of the watershed line (Figure 3). The important parameters in this case were the perpendicular distances evaluated and the elevation differences required. Two perpendicular distances were used, an inner and outer range. The inner range was related to the local element size by the size function and will be discussed in the vertical curvature parameters section. The minimum elevation difference required at the inner range was $0.3 \mathrm{~m}$. The outer range was fixed at $200 \mathrm{~m}$ throughout the mesh (Table 22). If a point on the watershed boundary line was at least $0.3 \mathrm{~m}$ above the terrain perpendicular at the variable inner range on both sides of the watershed line, and at least $0.5 \mathrm{~m}$ above the terrain perpendicular at a distance of $200 \mathrm{~m}$ on at least one side of the watershed line, it was declared significant (Figure 4a). If a vertex was not declared significant, it was further evaluated to determine if its elevation was more than $0.1 \mathrm{~m}$ below the surrounding 20,000 square meters of terrain (a square region with side lengths of approximately $141 \mathrm{~m}$ ) (Table 2). When the vertex met this criterion, it was declared insignificant. This evaluation generally prevents a feature line from being constructed across a flow path in a manner to block flow. Vertices that met neither of the criteria above were declared "continue" with the exception that the maximum length of consecutive continue points was not allowed to exceed $200 \mathrm{~m}$ (Figure 3). Further in the process, the ratio of "significant" vertices to total vertices in a line was considered and lines with a value lower than 0.35 were eliminated. 


\subsubsection{Vertical curvature parameters}

The objective of the vertical curvature evaluation is to limit the maximum error due to sub-grid scale raised features by placing an upper bound on their elevation error. The curvature evaluation calculates the elevation difference between each point on the extracted feature line and points perpendicular on either side of the feature at a distance equal to half of the planned element size as determined by the mesh size function. This evaluation is similar to calculating the maximum elevation error between the feature and the surrounding element's node elevations if the element were placed in the worst possible configuration (Figure $4 \mathrm{~b}$ and c). The elevation limit for this evaluation was $0.3 \mathrm{~m}$ (Table 2). As described in the previous section, if the elevation difference between the point on the feature line and both perpendicular points exceeded $0.3 \mathrm{~m}$, the vertical curvature criterion was met.

\subsubsection{Length parameters}

The length parameters are included to limit features to those long enough to influence flow. However, the practical purpose of the length parameters is to limit the number of disconnected line features that are included in the overall set. As the number of discrete features in a given area is increased, the quality of the mesh in the area decreases since adding a great number of features as element edges results in poorly shaped elements.

In the simplest form, an extracted line can be compared to a minimum line length parameter to decide if it should be included in the final line set. However, in practice the decision is more complicated because the initial extraction considering only the parameters listed in the above two sections 
1 generally results in a network of lines that intersect at several junctions.

2 Each line is weighted by a normalized value of the average elevation difference

3 between the ridge crest and the perpendicular elevation comparison locations.

${ }_{4}$ This weighting factor multiplied by the line length is used to determine the

5 priority for joining lines. A graph search routine is employed to connect the

6 features with the largest weighting factor to retain the highest features, which

7 promotes appropriate triangulation during the meshing procedure (Figure

8 3). For joining lines at junctions, lines are joined first with the maximum

9 possible weighting. These trunk lines were required to exceed 1,000 meters

10 to be included in the feature set (Figure 3). Additional lines that intersect

11

12

13

trunk lines were retained if they exceeded $500 \mathrm{~m}$ (Table 2).

\subsubsection{Vertex redistribution}

The next step in preparing the lines for inclusion in the mesh is to redistribute the line vertices to approximate the desired local element size, as the lines will form the edges of elements when imported to the mesh. The process again uses the initial finite element mesh as the size function for determining the desired local element size.

\subsubsection{Manual assessment}

The final step in preparing the lines for inclusion in the mesh is a manual assessment. Although the process is generally automated, visual inspection of the features is necessary before they are included in the mesh. The vertical feature lines are scanned for distances between separate lines, $\mathrm{du}$ plicate lines, small line segment angles, and disconnects between upstream and downstream valley lines. If two vertical feature line segments are within 
11.5 times the local element size, then they are trimmed. For example, if a 2 vertical feature line follows a road that passes over a creek, then the line 3 segments are trimmed to allow proper flow distribution through the creek.

4 Downstream and upstream valley lines are connected if they are considerably 5 close, and ends of line segments are trimmed if the angle is too sharp for the 6 local element size to appropriately follow.

7 The final number of vertical features for the three coastal counties in 8 Mississippi and Baldwin and Mobile Counties in Alabama exceeded 7,100 9 features lines including 3,786 ridge and 3,407 valley lines (Figure 5). Each 10 of the vertical features is an exact representation of the DEM at the vertices

along the feature line. The next step is to incorporate the vertical features into an unstructured mesh.

\subsection{Mesh generation}

Herein, mesh development is specific to the nearshore and floodplain regions of Mississippi and Alabama (Figure 1) and consists of two major steps; 1) node placement (i.e. meshing) and 2) interpolation of the elevation dataset to the mesh nodes. Offshore in the deep waters of the Gulf of Mexico and Atlantic Ocean, the mesh was based on recent models including the SL16, SL15, and earlier EC2001 tidal models [1, 29, 71]. The Louisiana floodplain, east of the Mississippi River is as described in the SL15/16 ADCIRC models and are included to allow the attenuation of storm surge that affects hydrodynamics along the Mississippi and Alabama coast.

During the mesh generation process, three variations of unstructured meshes were developed for the Mississippi and Alabama floodplains; $M S A L$, $M S A L \_n o V F \_z$, and $M S A L \_n o V F$. The $M S A L$ mesh contains vertical fea- 
1

tures along with their crest elevation; $M S A L \_n o V F_{-} z$ contains the same node placement as MSAL barring the crest elevation of the vertical features. The $M S A L \_n o V F$ mesh does not include vertical features, but is similar in node density as the $M S A L$ and $M S A L_{-} n o V F_{-} z$ meshes.

\subsubsection{Unstructured mesh node placement}

Two unstructured meshes were generated using vertical features as interior constraints, $M S A L$ and $M S A L_{-} n o V F_{-} z$, and were constructed as follows. The final set of vertical features (ridges and valleys), along with the shoreline and domain boundary, serve as the template, or conceptual model, for the placement of mesh nodes and the orientation of element edges across the floodplain. As stated prior, the final form of the vertical feature lines are a suite of lines that have their vertices redistributed according to a size function mesh. The minimum node spacing $(15 \mathrm{~m})$ is determined based on a target time step (here, 1 second) and the maximum node spacing (here, $200 \mathrm{~m}$ ) is estimated based on the maximum vertical elevation error. In regions of small meandering channels, large variation in topography or surface roughness, or areas of interest, element sizes are closer to the minimum, whereas regions near the inland boundary or areas outside the area of focus receive coarser node spacing. Additionally, spatially varying mesh resolution was determined from a rigorous topographic elevation error assessment presented in Bilskie et al. 3]. Since the vertices of the vertical feature lines have been appropriately redistributed along their length to match the local, spatially-varying mesh resolution, the lines can serve as the basis for the mesh generation.

Aquaveo SMS (Surface Water Modeling System) version 11.0 [72] was used to generate the unstructured mesh. SMS utilizes a scalar paving algo- 
rithm to place nodes and elements within a boundary. Element size within a polygon is based on the node vertex spacing of the boundary polygon, a size function dataset (scalar paving density), or both. The floodplain domain was decomposed and the mesh was generated from west to east, with internal mesh boundaries constructed from vertical feature lines. Once all of the internal meshes were complete, they were merged to form a single floodplain unstructured mesh. The third mesh, MSAL_noVF, was generated in a similar fashion; however, vertical features were not included. The outer floodplain and interior river and bay boundaries, as used for the MSAL and $M S A L \_n o V F_{-} z$ meshes, were the only constraints applied in mesh generation. This resulted in a mesh of similar nodal density across the floodplain, but mesh nodes and element faces were not aligned to vertical features.

Mesh resolution is appropriately $24 \mathrm{~km}$ in the deep Atlantic Ocean, 4 $\mathrm{km}$ in the Gulf of Mexico, and $500 \mathrm{~m}$ along the Mississippi/Alabama shelf. As shown in Figure 6a, mesh resolution along the barrier islands and within Mississippi Sound is as low as $60 \mathrm{~m}$ along the dredged shipping channels to a maximum of $200 \mathrm{~m}$ elsewhere. Resolution at the shoreline is generally consistent at $100 \mathrm{~m}$, but is as low as $15 \mathrm{~m}$ within narrow tidal creeks and canals. Overland mesh resolution ranges from $20 \mathrm{~m}$ to $100 \mathrm{~m}$ in the expected inundation zone, and coarsens to $200 \mathrm{~m}$ towards the mesh boundary along the highest elevations. The high resolution within Mississippi Sound and along the shoreline is necessary in order to capture the momentum transfer due to breaking waves. 


\subsubsection{Assignment (interpolation) of elevation}

Mesh nodes are assigned elevations using two types of criteria. A node is deemed a vertical feature node if it lies along a vertical feature line; otherwise it is attributed as a normal floodplain node. Vertical feature nodes are assigned elevations, via the DEM, based on direct lookup. That is, the value of the DEM grid cell the node resides in is assigned to that node, regardless of where it falls within the grid cell. This is done to ensure that the highest high or lowest low elevation is included in the mesh, according to the feature type of ridge or valley. All nodes are treated as normal floodplain nodes in the $M S A L \_n o V F \_z$ and $M S A L \_n o V F$ mesh. Normal floodplain mesh nodes obtain their elevations from the cell-area averaging $(C A A)$ interpolation method [3]:

$$
\begin{gathered}
N=\frac{\Delta_{M}}{4 * \Delta_{D E M}} \\
C A=\left\{\begin{array}{ccc}
1 & \text { for } & N<1 \\
{[2(N)+1]^{2}} & \text { for } & N \geq 1
\end{array}\right\}
\end{gathered}
$$

The $C A A$ interpolation scheme aims to minimize the vertical elevation error at a mesh node by averaging $C A$ number of DEM grid cell elevations about a given radius $(N)$, measured in the number of DEM cells. The radius varies from node to node and is based on the local element size $\left(\Delta_{M}\right)$ and DEM grid cell size $\left(\Delta_{D E M}\right)$. In regions of high element resolution (dense node spacing) the radius is small and in regions of coarse elements the radius is large. Figure 7 shows an example of the meshing and interpolation process for a site in Pascagoula, MS. For coastal Mississippi, errors between the 
unstructured mesh and source lidar range from about $11 \mathrm{~cm}$ to $70 \mathrm{~cm}$ with mesh elements ranging from $20 \mathrm{~m}$ to $160 \mathrm{~m}$, respectively [3].

The final MSAL and MSAL_noVF_z mesh contains 3,674,458 nodes and 7,318,668 elements; MSAL_noVF contains 3,743,067 nodes and 7,455,886 elements. Therefore, the computational cost among the three meshes are similar. Figure $6 \mathrm{~b}$ presents the MSAL ADCIRC model elevations (bathymetry and topography) for Mississippi and Alabama. Details in the elevations are evident in the shipping channels in Mississippi Sound, the variations of depths along the barrier islands, and rivers, including the Pascagoula and MobileTensaw among the numerous regions of low-lying salt marsh and narrow tidal creeks.

\subsection{Surface roughness parameters}

ADCIRC includes three spatially variable measures of surface roughness: bottom friction (Mannings $n$ coefficient), vertical shielding of wind due to dense canopies (surface canopy coefficient), and directional reduction of the wind (effective roughness length) based on the local landscape characteristics (i.e., skyscrapers, dense forest, or open water) [73]. In the floodplain, Manning's $n$ is spatially varying and assigned based on LULC. In this study, we utilize the Coastal Change Analysis Program (C-CAP) post-Katrina LULC dataset (http://www.csc.noaa.gov/digitalcoast/data/ccapregional/), other datasets such as the Mississippi Gap Analysis Program (MS-GAP) (http://www.basic.ncsu.edu/segap/index or the National Land Cover Database (NLCD) (http://www.mrlc.gov/). The advantage of C-CAP is it spans multiple states, therefore providing consistent coverage and classification types within the study domain. In addition, $\mathrm{C}$-CAP is well suited for classification of inter-tidal zones, the areas that are 
more likely to be flooded during a hurricane event. Mannings $n$ values for C-CAP LULC classifications are taken from Dietrich et al. [1] and listed in Table 3. For water bodies, bottom friction on the continental shelf is based on the composition of bottom sediments, sand (0.022) or mud (0.012) [74. In areas with depths less than $5 \mathrm{~m}$, Mannings $n$ is set to 0.025 along the shoreline and is interpolated based on depth to the local shelf value. In depths between $200 \mathrm{~m}$ and $5 \mathrm{~m}$, Mannings $n$ is set to the local shelf value, and depths greater than $200 \mathrm{~m}$, Mannings $n$ is set to 0.012. Narrow, shallow, meandering channels are assigned values of 0.03 to 0.035 [75, 76].

The surface (or wind) canopy adjustment accounts for the ability of the wind to penetrate the canopy and transfer momentum to the water column. In densely forested canopies, there is negligible transfer of momentum due to the forest canopy shielding the water surface from the wind stress, ultimately creating a stratified two layer system [73, 77]. Canopy is interpolated onto the mesh nodes in a similar fashion as Mannings $n$. The C-CAP grid cell that lies on the ADCIRC mesh node is determined and the canopy value for the given land cover class is assigned to the node. The LULC classes are mapped and converted to their respective canopy coefficient, 1 (no canopy) or 0 (canopy) (Table 3).

The anisotropic $z_{0}$ value reduces wind speed at a location based on upwind conditions. This is especially important in the nearshore region where there are drastic discrepancies between the wind reduction potential of vegetated land and open water. This evolution of wind direction throughout the duration of the storm event alters wind speed from marine based winds to wind reduced by dense obstructions (buildings, forest, etc) located upwind 
1 of a point. ADCIRC employs twelve $z_{0}$ values at each mesh node (i.e., every 230 compass degrees). Assignment of $z_{0}$ values at each mesh node involves 3 assembling LULC classes in a wedge-shaped region upwind of the node for 3 $4 \mathrm{~km}$. Table 3 shows $z_{0}$ values for C-CAP LULC classes. ADCIRC determines 5 the correct $z_{0}$ value to apply based on the instantaneous local wind direction 6 at runtime [73].

\section{2.7. Vertical datum offset}

The MSAL mesh elevations are referenced to NAVD88 (North American 9 Vertical Datum of 1988), but the SWAN+ADCIRC model should be initiated

with water surface elevations at zero mean sea level (MSL). To account for local differences between MSL and NAVD88, a vertical datum offset was established. To adjust the vertical datum from NAVD88 to MSL, an offset of $0.13 \mathrm{~m}$ is added to the model [29]. An additional offset must be added to account for the seasonal variation in the Gulf of Mexico due to thermal expansion of the upper stratum of the water column; the offset was $0.10 \mathrm{~m}$, based on analysis of local NOAA tide gage stations. Therefore, the initial water level in the model was set to $0.23 \mathrm{~m}(0.13 \mathrm{~m}+0.10 \mathrm{~m})$.

\subsection{Meteorological and tidal forcing}

The simulated flood event is Hurricane Katrina as it has been extensively studied and well validated in terms of its wind field and flooding [29, 78, 79, 18, 80]. Additionally, Katrina generated unprecedented water levels and inundation extent in coastal Mississippi, thereby putting sufficient stress on the developed overland meshing techniques for testing. Therefore, 
each mesh is included in a SWAN+ADCIRC simulation for Hurricane Katrina. The simulation begins from a cold start on 08/15/2005 12:00 UTC and forced with astronomic tides for 10 days, beginning with a 7 day hyperbolic ramp to establish a dynamic steady state. The astronomic tides $\left(O_{1}, K_{1}, P_{1}, Q_{1}, M_{2}, S_{2}, N_{2}\right.$, and $\left.K_{2}\right)$, derived from Oregon State's TPXO7.2 tidal atlas [81, 82], are forced along the open ocean boundary $\left(60^{\circ} \mathrm{W}\right.$ meridian), in deep water, where tidal amplitudes and phases are well known. Wind forcing and wave radiation stresses are added on 08/25/2005 12:00 UTC for 5 days, yielding a total simulation length of 15 days. Simulated wind speed and direction, significant wave height, wave direction, mean and peak wave period, and water surface elevations will be compared to recorded data.

Wind and pressure fields for Katrina were developed using a blend of objectively analyzed measurements and modeled winds and pressures as described in Bunya et al. [29]. This study applies the same Katrina inputs as Bunya et al. [29] and Bilskie et al. [14], which used $\mathrm{H}^{*}$ Wind [79] analysis in the core of the system. The approach in developing the tropical wind and pressure fields has been documented and verified in numerous ocean response studies including Hope et al. [64] (Ike 2008), Dietrich et al. [1] (Gustav 2008), Bacopoulos et al. [83] (Jeanne 2004), and Bunya et al. [29] (Katrina and Rita 2005).

\subsection{Design of experiment}

Three experiments were performed to examine the influence of vertical features on mesh elevations and water levels due to hurricane storm surge. Each of the three meshes were included in a hydrodynamic simulation representation of Hurricane Katrina and model results were compared to measured 
time-series water levels, HWMs, and post-storm aerial images of debris lines.

\section{3. Results and discussion}

\section{3.1. Time-series water levels comparison}

Each of the unstructured meshes ( $\left.M S A L, M S A L_{-} n o V F_{-} z, M S A L_{-} n o V F\right)$ were included in an hydrodynamic simulation representative of Hurricane Katrina using the SWAN+ADCIRC code and model setup described above. For each simulation, simulated time-series of water surface elevations were compared to observed data. The observed water surface elevations were obtained from NOAA, USACE, and USGS gage stations throughout Mississippi and Alabama (Figure 8). Figure 9 presents the time-series water levels for the observed and modeled data at a select number of stations within the nearshore region. At all locations, the simulated water surface elevations among the three simulations are similar; no substantial differences are observed. The modeled water levels match the amplitude and phase of the astronomic tide signal leading up to the main surge event, and the models match the rising water surface elevation, peak surge (if recorded in the observed data), and falling limb of the hydrograph. To quantify errors between simulated and observed time-series water levels, Scatter Index (SI) and bias metrics were computed [84, 64]:

$$
S I=\frac{\sqrt{\frac{1}{N} \sum_{i=1}^{N}\left(E_{i}-\bar{E}\right)^{2}}}{\frac{1}{N} \sum_{i=1}^{N}\left|O_{i}\right|}
$$




$$
\text { bias }=\frac{\frac{1}{N} \sum_{i=1}^{N} E_{i}}{\frac{1}{N} \sum_{i=1}^{N}\left|O_{i}\right|}
$$

1 where $N$ is the number of data points, $E$ is the error between the model $2\left(M_{i}\right)$ and observed $\left(O_{i}\right)$ value $\left(E_{i}=M_{i}-O_{i}\right)$, and $\bar{E}$ is the mean error. 3 Since the computed error metrics were similar among the three experimental 4 simulations, only the $M S A L$ model result error metrics are shown and are 5 translatable to the other simulations. SI and bias for stations that included 6 reliable water surface elevation time-series for the entirety of the storm event 7 were computed. The NOAA stations yielded an SI of 0.12 and a bias of -0.01. 8 The USACE and USGS stations yielded an SI of 0.25 and -0.26 , and a bias 9 of -0.01 and -0.05 , respectively (Table 4). All 22 stations for which statistics

were computed yielded a weighted average SI of 0.22 and bias of -0.02 (with respect to the number of stations).

Using the traditional, point-based, time-series water surface elevation validation technique, all three model simulations produced accurate results. There was no discernible difference in the statistics among the simulated $M S A L, M S A L \_n o V F_{-} z$, and $M S A L \_n o V F$ water surface elevations when compared to the observed data at the gages. This is caused by the fact that the gages are located in open water, and the results are not sensitive to differences in inundation across the floodplain. The methods by which the floodplain is included in the unstructured mesh did not alter the results at the gages, as long as the floodplain is included to allow storm surge attenuation [85]. With this, focus is turned to the assessment of each of the models performance within the floodplain and begins with a comparison of observed 
HWMs.

\section{3.2. High water mark comparison}

There are a total of 340 HWMs recorded by FEMA and the USACE throughout Mississippi and Alabama in the wake of Hurricane Katrina. A HWM model performance analysis was conducted in which all available measured HWMs were compared to the simulated maximum water level for each of the three simulations. The HWMs were plotted and the $95 \%$ confidence interval (CI) was computed:

$$
C I_{95}=\bar{E} \pm 1.96 * \sigma
$$

3 where $\bar{E}$ is the mean error and $\sigma$ the standard deviation of the errors. $C I_{95}$ 4 was used to determine outliers in the HWMs for closer inspection of error 5 in the measurements or errors within the SWAN+ADCIRC model. HWMs 6 were removed if they met one of the following conditions: 1) The HWM was 7 suspected to be the result of surface runoff or flooding due to precipitation 8 and not storm surge, 2) the field HWM was suspected to have errors, or 3) the HWM resided outside the computed $95 \%$ confidence interval. To determine if a HWM was caused by precipitation and not storm surge, the location of the point was considered along with peak surge values from neighbouring HWMs.

12 If the point was located near a stream and significantly upstream, and nearby HWMs included lower measurements, then the point was removed. In some

instances, these HWMs were obtained from storm tide sensors which made it easy to determine if the peak was caused by surface runoff. Additionally, a HWM was removed if it was found on the upstream side of a culvert; this introduces numerous sources of error such as a clogged culvert pipe or 
1 backwater effects. For the second criteria, we examined field notes for the 2 HWMs and removed them if key words in the field report such as "poor 3 debris line" or "clogged culvert" were found. For the third criteria, HWMs 4 that included error that lie outside the $C I_{95}$ were removed. $61 \mathrm{~m}$, for each simulation. A majority of the HWMs that were removed 7 resided along Little Lagoon, west of Fort Morgan Peninsula. ADCIRC under8 predicted maximum water levels along this region which appeared to be 9 caused by high water levels within the lagoon itself. Hurricanes Katrina and 10 Ivan (2004) triggered the formation of an inlet west of the original, which

would lead to an increase in flooding of the lagoon and across the peninsula [86]. In addition, since the $M S A L$ model was constructed from the most recent lidar data available, per FEMA guidance, this region contained postKatrina lidar. The current dune heights represented by the MSAL model are about $1 \mathrm{~m}$ higher than pre-Katrina dune heights, which prevented overtopping of the peninsula in the simulation, and therefore lower water levels within the lagoon.

After the error analysis from the first two conditions, 19 HWMs were eliminated, and 321 remained for the comparison to simulated maximum water levels and analysis of the $95 \%$ confidence interval (Table 4). The $M S A L$ resulted in further elimination of 19 HWMs based on the confidence interval analysis. Of the $302 \mathrm{HWMs}, 274(90.7 \%)$ were within $\pm 0.5 \mathrm{~m}$. Similarly, the CI analysis for the $M S A L_{-} n o V F_{-} z$ and $M S A L_{-} n o V F$ resulted in elimination of 19 and $20 \mathrm{HWMs}$, and $273(90.4 \%)$ and $270(89.1 \%)$ were within \pm 0.5 $\mathrm{m}$, respectively. The slope of the line of best-fit, for all experiments, is 1.0 
1 with an $R^{2}$ of 0.97 (Figure 10). The mean absolute error (MAE), standard 2 deviation (SD) and upper and lower 95\% CI were similar (5).

Results did not improve or diminish among the three experiments with 4 respect to the HWM analysis, which was an unanticipated result of this work.

5 Numerous HWMs were located in regions where vertical features influenced 6 inundation extent; however, the simulated water surface elevation at the 7 HWM locations were not altered by the vertical features, only the flooding 8 extent. This is addressed in the following section, and it is shown that

the inclusion of vertical features increases model accuracy with respect to inundation extent.

\subsection{Post-Katrina aerial imagery comparison}

Post-Katrina aerial photographs captured by NOAA revealed the wide spread damage caused by Hurricane Katrina (http://ngs.woc.noaa.gov/storms/katrina/).

The imagery enables a qualitative model validation of inundation extent, particularly along local high elevation gradients, such as near vertical features. Turning focus to coastal Mississippi, specifically near Gulfport, similar flooding extent is observed between the $M S A L$ and $M S A L_{-} n o V F_{-} z$ simulations, although there were some minor increases in inundation extent. On the other hand, the MSAL_noVF model estimated flooding further inland. Here, simulated inundation between the $M S A L$ and $M S A L_{-} n o V F_{-} z$ were compared to the debris line found in the NOAA post-Katrina aerial imagery. The first image is located just west of Gulfport Harbor and between E. Beach Blvd. and E. Railroad St. Figure 11 shows that inundation was blocked by E. Railroad St. in the MSAL model, but is not the case in the MSAL_noVF model result (Figure 11b). E. Railroad St. is included in the MSAL model 
1 as a vertical feature. In other words, surge propagated past E. Railroad St. 2 as if it were not there (or had similar elevation to the surrounding land). 3 Close inspection of the aerial image depicts a debris line between and along 4 E. Railroad St. and 2nd St. From the image, there is no discernible debris 5 north of Railroad St. caused by storm surge; however, some debris may be 6 present, but was likely caused by wind than surge. Although there is debris 7 along E. Railroad St., and it is likely that surge piled up along the roadway, s the $M S A L$ model is not able to inundate up to the roadway due to the limi9 tation of the local element size ( 60-100 $\mathrm{m}$ in this location) and the wetting 10 and drying algorithm. In order to simulate inundation closer to the road-

way, without removing the vertical feature, would be to decrease the local element size sub-20 m. Additionally, the SWAN+ADCIRC model simulation does not include wave-induced runup. Regardless, the $M S A L$ model appropriately simulates the inundation front and inhibits surge from incorrectly overtoping E. Railroad St. at this location.

The HWM at this location has a value of $7.59 \mathrm{~m}$ (NAVD88) and a simulated error of $-0.25 \mathrm{~m}$. The location of the HWM demonstrates the cause for the similar HWM errors among the three models. Since the models without correct vertical feature representation generally increased flooding extent, the location of the HWM were inundated in all three model simulations. The simulated maximum water surface elevation at this HWM location would not be expected to vary due to the overtopping of the ridge feature. The only plausible scenario in which the maximum water surface elevations were expected to be different is if the ridge feature had a drastically higher elevation than the surrounding terrain and surge accumulated, but never overtopped 
the roadway, yielding a large maximum water surface elevation. This water surface elevation would be higher than if the roadway was not described and surge was not able to pile up and inundate the region north of the roadway.

Moving east along the coast, Figure 11k and 11d depict a similar story. There is a tremendous amount of debris between E. Railroad St. and the shoreline, but not north. The $M S A L$ correctly represents the storm surge inundation. However, the $M S A L_{-} n o V F_{-} z$ model result yields overtopping of E. Railroad St. This is incorrect when examining the debris line. The measured HWM in this region is $7.25 \mathrm{~m}$ (NAVD88), with a simulated error of $-0.09 \mathrm{~m}$. As previously described, the maximum storm surge is not expected to vary drastically as because both models simulated flooding this region. Similar findings would be obtained regardless of the number of HWMs collected. This indicates that state-of-the-art flood inundation models, and storm surge models in particular, are now becoming accurate enough that traditional point-based validation methods (e.g. gage based time-series and HWM comparison), which are acceptable in comparing total water levels, are limited in their ability to validate inundation extent ([87]).

The comparison of storm surge inundation extent against post-event imagery allows a semi-empirical validation beyond point-based methods of maximum water levels. This enables a more rigorous validation and exhibits the necessity for having accurate terrain data in the flood inundation model, specifically vertical features. From this analysis, it is evident that the $M S A L$ model better represents the extent of inundation and is therefore a more accurate surge model than the other two models, without reliance on hand digitization or sacrificing computational cost. 


\subsection{Flooding extent comparison}

2

In order to determine the impact of the additional flooding extent from the $M S A L_{-} n o V F_{-} z$ and $M S A L_{-} n o V F$ models, each were categorized into inundated regions with and without urban infrastructure. The 2006 postKatrina CCAP LULC was sorted and binned into two land classifications, urban and rural within Mississippi and Alabama (open water was left out of this reclassification). For each of the two classes, the additional inundated area was computed from the $M S A L_{-} n o V F_{-} z$ and $M S A L_{-} n o V F$ simulations. $M S A L \_n o V F_{-} z$ inundated an additional $1.5 \mathrm{~km}^{2}$ and $9 \mathrm{~km}^{2}$ for urban and rural area, and $M S A L \_n o V F$ inundated an additional $10.3 \mathrm{~km}^{2}$ and $44.8 \mathrm{~km}^{2}$, respectively. To expand these results further, the urban space is related to population density. The city of Gulfport, MS has a population density of 730.61 people per square $\mathrm{km}$ and contains 340.60 housing units per square km (http://www.gulfport-ms.gov/census.shtml). Extrapolating this population density across the Mississippi-Alabama coast may result in an additional 1,096 people and 511 housing units affected in using the $M S A L_{-} n o V F_{-} z$ model and 7525 people and 3508 housing units with the MSAL_noVF model results. This result may be of critical importance when designing and operating a real time forecasting flood inundation model, especially when used to guide evacuation planning and the deployment of first responders.

In addition to modifying inundation extent, the inclusion of vertical features also altered the timing of the flood and recession wave. In using the MSAL_noVF model, some regions flooded several hours earlier than the $M S A L$ model, especially along highways that are overtopped. Furthermore, not only did the inclusion of raised features limit overtopping during the in- 
coming flood, but also inhibits the recession of the flood as it flows back to the ocean.

\section{Summary and conclusions}

To accurately represent overland flooding due to hurricane storm surge, it is imperative that the numerical model includes an accurate representation of the overland terrain. We employed a novel and largely reproducible framework to guide semi-automatic unstructured mesh generation across a coastal floodplain via the inclusion of vertical terrain features and accurate assignment of mesh nodes using a bare earth lidar-derived DEM. These methods administered the density and location of mesh nodes and alignment of element edges as guided by the landscape. Therefore, it is recommend that the DEM be developed before mesh generation begins so as to to link the natural terrain to the unstructured mesh and ultimately to the flood inundation model. These semi-automated approaches were scaled and applied for the generation of a wind-wave hurricane storm surge model for the Mississippi and Alabama coast. The influence of vertical features on the model's portrayal of the floodplain elevations were examined in addition to the response of water levels and inundation extent among three unstructured meshes representative of the Mississippi-Alabama coastal floodplain. The MSAL mesh included vertical features, $M S A L \_n o V F_{-} z$ contained vertical features in the mesh topology, but crown elevations were withheld, and the MSAL_noVF mesh included similar mesh resolution as the other meshes, although no vertical features were included.

The three unstructured meshes were employed to simulate shallow water 
hydrodynamics for Hurricane Katrina (2005) using the coupled SWAN+ADCIRC

2 model framework. The model was parameterized to represent natural geo3 physical conditions across the floodplain, thereby removing the need for 4 model calibration. Simply put, the model was setup with the best known and 5 scientifically defensible conditions and no calibration/tuning was performed 6 herein. The methods presented are not limited to storm surge models, but 7 can be utilized in river flood routing models that require spatial domain 8 discretization.

It was shown that the state at which flood inundation models are currently 10 being developed require additional validation techniques beyond point-based methods, and in particular, the validation of inundation extent. Each model

was compared to time-series water surface elevations, post-event measured HWMs, and post-event aerial imagery. For each model, the time-series water levels matched the observed data well and captured the tides before landfall and the rising limb of the storm surge hydrograph. Katrina simulated water level peaks also compared well with an $R^{2}$ of 0.97 and upper and lower $95 \%$ confidence interval of $\sim \pm 0.60 \mathrm{~m}$. From the point-based validation, it was not readily clear which of the three model experiments performed best in terms of accuracy. Examination of inundation extent among the three model results was compared to debris lines derived from post-event aerial imagery. From the aerial imagery comparison, the $M S A L$ model produced the more accurate simulated inundation extent, followed by the $M S A L_{-} n o V F_{-} z$, and $M S A L \_n o V F$ model. This result was obtained without reliance on hand digitization or sacrificing computational cost as the mesh node count was similar among the three models. 
Comparison of differences in total flooding area and inundation extent resulted in the MSAL model having the lesser amount of flooded area than the other two models. Relating the additional differences in inundation extent to population density along coastal Mississippi resulted in a possible affected population of 1,096 people and 7,525 people when using inundation results from the $M S A L_{-} n o V F_{-} z$ and $M S A L_{-} n o V F$ model. Model results also indicated that vertical features have a role in the timing of the initial flood wave as well as the surge recession, which may be critical when using inundation models in a real time forecasting framework. Additionally, the methods presented herein may have an impact on transport models (including debris transport).

Accurate results were computed in the $M S A L$ due to the methods employed in generating the unstructured mesh, which describes the varying types of topography across the landscape. Areas that exhibited substandard model results are found in regions with coarse mesh resolution, unsatisfactory elevation or bathymetric data, narrow rivers and canals, and regions dominated by surface runoff and local flooding. Additionally, inclusion of event-scale coastal erosion, surface runoff generating mechanisms and overland flow, flow description through narrow channels and tidal creeks, better descriptions of salt marsh table elevations, and improved surface roughness characteristics can increase the accuracy of the model through the inclusion of these additional physical processes.

Although narrowing, there remains a gap in the knowledge of relating the physics with numerical discretization of a continuous and natural surface. As this work is a step towards fully-automated mesh generation for 

6 ideal mesh.

shallow water hydrodynamics, future research should include an evaluation of the extraction algorithm parameters across difference landscapes, in addition to mesh resolution sensitivity coupled with vertical feature integration.

The guidance and constraints presented here may promote coarser model resolution without sacrificing model accuracy, and in term will lead to a more

\section{Acknowledgements}

This research was funded in part under award NA10NOS4780146 from the National Oceanic and Atmospheric Administration (NOAA) Center for Sponsored Coastal Ocean Research (CSCOR), award number NFWMD-08073 from the Northwest Florida Water Management District (NWFWMD) and the Louisiana Sea Grant Laborde Chair endowment. This work used the STOKES Advanced Research Computing Center (ARCC) (webstokes.ist.ucf.edu) and Extreme Science and Engineering Discover Environment (XSEDE), which is supported by the National Science Foundation grant number ACI-1053575.

The authors also wish to thank C. Dietrich and Z. Cobell for their expertise with the SWAN+ADCIRC model, and the editor and reviewers for their constructive comments. The statements and conclusions are those of the authors and do not necessarily reflect the views of NOAA or the NWFWMD. The authors also wish to thank the four anonymous reviewers for their invaluable comments and suggestions that helped to improve the manuscript

[1] J. Dietrich, J. Westerink, A. Kennedy, J. Smith, R. Jensen, M. Zijlema, L. Holthuijsen, C. Dawson, R. Luettich, M. Powell, V. Cardone, A. Cox, G. Stone, H. Pourtaheri, M. Hope, S. Tanaka, L. Wes- 
terink, H. Westerink, Z. Cobell, Hurricane gustav (2008) waves and storm surge: Hindcast, synoptic analysis, and validation in southern louisiana, Monthly Weather Review 139 (8) (2011) 2488-2522. doi: 10.1175/2011MWR3611.1.

URL http://dx.doi.org/10.1175/2011MWR3611.1

[2] B. F. Sanders, J. E. Schubert, R. L. Detwiler, Parbrezo: A parallel, unstructured grid, godunov-type, shallow-water code for high-resolution flood inundation modeling at the regional scale, Advances in Water Resources 33 (12) (2010) 1456-1467.

[3] M. Bilskie, S. C. Hagen, Topographic accuracy assessment of bare earth lidar-derived unstructured meshes, Advances in Water Resources 52 (2013) 165-177. doi:10.1016/j .advwatres . 2012.09.003.

URL http://www.sciencedirect.com/science/article/pii/ S0309170812002503?v=s5

[4] S. Medeiros, Incorporating remotely sense data into coastal hydrodynamic models: Parameterization of surface roughness and spatiotemporal validation of inundation area, Thesis (2012).

[5] P. D. Bates, K. J. Marks, M. S. Horritt, Optimal use of high-resolution topographic data in flood inundation models, Hydrological Processes 17 (3) (2003) 537-557. doi:10.1002/hyp.1113.

URL http://dx.doi.org/10.1002/hyp.1113

[6] J. Shen, K. Zhang, C. Xiao, W. Gong, Improved prediction of storm surge inundation with a high-resolution unstructured grid model, Jour- 
nal of Coastal Research (2006) 1309-1319doi:10.2112/04-0288.1.

URL http://www . jcronline.org/doi/abs/10.2112/04-0288.1

[7] B. Kim, B. F. Sanders, J. E. Schubert, J. S. Famiglietti, Mesh type tradeoffs in 2d hydrodynamic modeling of flooding with a godunovbased flow solver, Advances in Water Resources 68 (0) (2014) 42-61. doi:http://dx.doi.org/10.1016/j.advwatres.2014.02.013. URL http://wWW.sciencedirect.com/science/article/pii/ S0309170814000360

[8] J. E. Schubert, B. F. Sanders, Building treatments for urban flood inundation models and implications for predictive skill and modeling efficiency, Advances in Water Resources 41 (0) (2012) 49-64. doi:http://dx.doi.org/10.1016/j.advwatres.2012.02.012. URL http://wwW.sciencedirect.com/science/article/pii/ S0309170812000425

[9] R. Tsubaki, I. Fujita, Unstructured grid generation using lidar data for urban flood inundation modelling, Hydrological Processes 24 (11) (2010) 1404-1420. doi:10.1002/hyp.7608.

URL http://dx.doi.org/10.1002/hyp.7608

[10] A. W. Niedoroda, D. T. Resio, G. R. Toro, D. Divoky, H. S. Das, C. W. Reed, Analysis of the coastal mississippi storm surge hazard, Ocean Engineering 37 (1) (2010) 82-90. doi:http://dx.doi.org/10.1016/j.oceaneng.2009.08.019. URL http://wwW.sciencedirect.com/science/article/pii/ S0029801809002157 
[11] S. Hagen, P. Bacopoulos, S. Medeiros, D. Coggin, M. Salisbury, J. Atkinson, H. Roberts, Storm surge modeling for fema map modernization for franklin, wakulla, and jefferson counties, florida, Report, University of Central Florida (2009).

[12] Z. Cobell, H. Zhao, H. J. Roberts, F. R. Clark, S. Zou, Surge and wave modeling for the louisiana 2012 coastal master plan, Journal of Coastal Research (2013) 88-108doi:10.2112/SI_67_7. URL http://www .jcronline.org/doi/abs/10.2112/SI_67_7

[13] J. C. Dietrich, C. N. Dawson, J. M. Proft, M. T. Howard, G. Wells, J. G. Fleming, J. Luettich, R. A., J. J. Westerink, Z. Cobell, M. Vitse, H. Lander, B. O. Blanton, C. M. Szpilka, J. H. Atkinson, Real-Time Forecasting and Visualization of Hurricane Waves and Storm Surge Using SWAN+ADCIRC and FigureGen, Vol. 156 of The IMA Volumes in Mathematics and its Applications, Springer New York, 2013, book section 3, pp. 49-70. doi:10.1007/978-1-4614-7434-0_3.

URL http://dx.doi .org/10.1007/978-1-4614-7434-0_3

[14] M. Bilskie, S. Hagen, S. C. Medeiros, D. Passeri, Dynamics of sea level rise and coastal flooding on a changing landscape, Geophysical Research Letters 41 (3) (2014) 927-934. doi:10.1002/2013GL058759.

URL http: //dx.doi .org/10.1002/2013GL058759

[15] J. Atkinson, J. Smith, C. Bender, Sea-level rise effects on storm surge and nearshore waves on the texas coast: influence of landscape and storm characteristics, Journal of Waterway, Port, Coastal, and Ocean Engineering 139 (2) (2013) 98-117. 
[16] J. M. Smith, M. A. Cialone, T. V. Wamsley, T. O. McAlpin, Potential impact of sea level rise on coastal surges in southeast louisiana, Ocean Engineering 37 (2010) 37-47.

[17] Z. Yang, T. Wang, N. Voisin, A. Copping, Estuarine response to river flow and sea-level rise under future climate change and human development, Estuarine, Coastal and Shelf Science (0). doi:http://dx.doi.org/10.1016/j.ecss.2014.08.015.

URL http://www.sciencedirect.com/science/article/pii/

S0272771414002303

[18] Z. Yang, T. Wang, R. Leung, K. Hibbard, T. Janetos, I. Kraucunas, J. Rice, B. Preston, T. Wilbanks, A modeling study of coastal inundation induced by storm surge, sea-level rise, and subsidence in the gulf of mexico, Natural Hazards 71 (3) (2014) 1771-1794. doi: 10.1007/s11069-013-0974-6.

URL http://dx.doi.org/10.1007/s11069-013-0974-6

[19] S. Hagen, J. Morris, P. Bacopoulos, J. Weishampel, Sea-level rise impact on a salt marsh system of the lower st. johns river, J. Waterway, Port, Coastal, Ocean Eng. 139 (2) (2013) 118-125.

[20] J. E. Schubert, B. F. Sanders, M. J. Smith, N. G. Wright, Unstructured mesh generation and landcover-based resistance for hydrodynamic modeling of urban flooding, Advances in Water Resources 31 (12) (2008) 1603-1621. doi:http://dx.doi.org/10.1016/j.advwatres. 2008.07.012. 
URL http://www.sciencedirect.com/science/article/pii/ S0309170808001279

[21] G. Sofia, G. D. Fontana, P. Tarolli, High-resolution topography and anthropogenic feature extraction: testing geomorphometric parameters in floodplains, Hydrological Processes 28 (4) (2014) 2046-2061. doi: 10.1002/hyp.9727.

URL http://dx.doi.org/10.1002/hyp.9727

[22] C. M. M. Steinfeld, R. T. Kingsford, S. W. Laffan, Semi-automated gis techniques for detecting floodplain earthworks, Hydrological Processes 27 (4) (2013) 579-591. doi:10.1002/hyp.9244.

URL http://dx.doi.org/10.1002/hyp.9244

[23] P. D. Bates, M. D. Wilson, M. S. Horritt, D. C. Mason, N. Holden, A. Currie, Reach scale floodplain inundation dynamics observed using airborne synthetic aperture radar imagery: Data analysis and modelling, Journal of Hydrology 328 (12) (2006) 306-318. doi:http://dx.doi.org/10.1016/j.jhydrol.2005.12.028.

URL http://www.sciencedirect.com/science/article/pii/ S0022169406000047

[24] M. J. Purvis, P. D. Bates, C. M. Hayes, A probabilistic methodology to estimate future coastal flood risk due to sea level rise, Coastal Engineering 55 (12) (2008) 1062-1073. doi:http://dx.doi.org/10.1016/j.coastaleng.2008.04.008. URL http://www.sciencedirect.com/science/article/pii/ S0378383908000811 
[25] J. Shewchuk, Triangle: Engineering a 2D quality mesh generator and Delaunay triangulator, Vol. 1148 of Lecture Notes in Computer Science, Springer Berlin Heidelberg, 1996, book section 23, pp. 203-222. doi: 10.1007/BFb0014497.

URL http://dx.doi.org/10.1007/BFb0014497

[26] T. W. Gallien, J. E. Schubert, B. F. Sanders, Predicting tidal flooding of urbanized embayments: A modeling framework and data requirements, Coastal Engineering 58 (6) (2011) 567-577. doi:http://dx.doi.org/10.1016/j.coastaleng.2011.01.011. URL http://www.sciencedirect.com/science/article/pii/ S0378383911000123

[27] R. Luettich, J. Westerink, Formulation and numerical implementations of the $2 \mathrm{~d} / 3 \mathrm{~d}$ adcirc finite element model version 44.xx (2004). URL http://www .adcirc.org/adcirc_theory_2004_12_08.pdf

[28] J. Westerink, R. Luettich, J. Feyen, J. Atkinson, C. Dawson, H. Roberts, M. Powell, J. Dunion, E. Kubatko, H. Pourtaheri, A basin- to channelscale unstructured grid hurricane storm surge model applied to southern lousiana, Monthly Weather Review 136 (2008) 833-864. doi:http:// dx.doi.org/10.1175/2007MWR1946.1.

[29] S. Bunya, J. Dietrich, J. Westerink, B. Ebersole, J. Smith, J. Atkinson, R. Jensen, D. Resio, R. Luettich, C. Dawsone, V. Cardone, A. Cox, M. Powell, H. Westerink, H. Roberts, A high-resolution coupled riverine flow, tide, wind, wind wave, and storm surge model for southeastern 
louisiana and mississippi. part i: Model development and validation, Monthly Weather Review 128 (345-377). doi:10.1175/2009MWR2906.1.

[30] M. Palaseanu-Lovejoy, C. A. Thatcher, J. A. Barras, Levee crest elevation profiles derived from airborne lidar-based high resolution digital elevation models in south louisiana, ISPRS Journal of Photogrammetry and Remote Sensing 91 (0) (2014) 114-126. doi:http://dx.doi.org/10.1016/j.isprsjprs.2014.02.010. URL http://www.sciencedirect.com/science/article/pii/ S0924271614000471

[31] P. Passalacqua, P. Belmont, E. Foufoula-Georgiou, Automatic geomorphic feature extraction from lidar in flat and engineered landscapes, Water Resources Research 48 (3) (2012) W03528. doi:10.1029/ 2011WR010958.

URL http://dx.doi.org/10.1029/2011WR010958

[32] E. G. Johnston, A. Rosenfeld, Digital detection of pits, peaks, ridges, and ravines, Systems, Man and Cybernetics, IEEE Transactions on SMC-5 (4) (1975) 472-480. doi:10.1109/TSMC. 1975.5408443.

[33] S. Jenson, J. Domingue, Extracting topographic structure from digital elevation data for geographic information system analysis, Photogrammetric Engineering and Remote Sensing 54 (11) (1988) 1593-1600.

[34] A. Meisels, S. Raizman, K. Arnon, Skeletonizing a dem into a drainage network, Computers and Geosciences 21 (1) (1995) 187-196. 
[35] B. Lohani, D. C. Mason, Application of airborne scanning laser altimetry to the study of tidal channel geomorphology, ISPRS Journal of Photogrammetry and Remote Sensing 56 (2) (2001) 100-120. doi:http://dx.doi.org/10.1016/S0924-2716(01)00041-7.

URL http://www.sciencedirect.com/science/article/pii/ S0924271601000417

[36] D. C. Mason, T. R. Scott, H.-J. Wang, Extraction of tidal channel networks from airborne scanning laser altimetry, ISPRS Journal of Photogrammetry and Remote Sensing 61 (2) (2006) 67-83. doi:http://dx.doi.org/10.1016/j.isprsjprs.2006.08.003. URL http://www.sciencedirect.com/science/article/pii/ S092427160600092X

[37] R. Koenders, R. C. Lindenbergh, J. E. A. Storms, M. Menenti, Multiscale curvatures for identifying channel locations from dems, Computers and Geosciences 68 (0) (2014) 11-21. doi:http://dx.doi.org/10.1016/j.cageo.2014.03.016.

URL http://www.sciencedirect.com/science/article/pii/ S0098300414000764

[38] T. K. Peucker, D. H. Douglas, Detection of surface-specific points by local parallel processing of discrete terrain elevation data, Computer Graphics and Image Processing 4 (4) (1975) 375-387. doi:http://dx.doi.org/10.1016/0146-664X(75)90005-2. URL http://www.sciencedirect.com/science/article/pii/ $0146664 \times 75900052$ 
[39] Z. Chen, J. Guevara, Systematic selection of very imporant points (vip) from digital terrain model for constructing triangular irregular networks, in: AutoCarto 8, ASPRS/ACSM, pp. 50-56.

[40] J. A. Y. Lee, Comparison of existing methods for building triangular irregular network, models of terrain from grid digital elevation models, International Journal of Geographical Information Systems 5 (3) (1991) 267-285. doi:10.1080/02693799108927855.

URL http://dx.doi .org/10.1080/02693799108927855

[41] C. Briese, Three-dimensional modelling of breaklines from airborne laser scanner data, in: International Society for Photogrammetry and Remote Sensing (ISPRS), XXth ISPRS Congress, pp. 12-23.

[42] A. Brzank, P. Lohmann, C. Heipke, Automated extraction of pair wise structure lines using airborne laserscanner data in coastal areas, in: ISPRS WG III/3, III/4, V/3 Workshop "Laser Scanning 2005".

[43] I. S. Kweon, T. Kanade, Extracting topographic terrain features from elevation maps, CVGIP: Image Underst. 59 (2) (1994) 171-182. doi: 10.1006/ciun.1994.1011.

[44] C. Steger, Unbiased extraction of curvilinear structures from $2 \mathrm{~d}$ and $3 \mathrm{~d}$ images, Thesis (1998).

[45] J. F. O'Callaghan, D. M. Mark, The extraction of drainage networks from digital elevation data, Computer Vision, Graphics, and Image Processing 28 (3) (1984) 323-344. doi:http: //dx.doi.org/10.1016/S0734-189X (84)80011-0. 
URL http://www.sciencedirect.com/science/article/pii/ S0734189X84800110

[46] D. Tarboton, D. Ames, Advances in the mapping of flow networks from digital elevation data, in: Proceedings of the World Water and Environmental Resources Congress, ASCE.

[47] D. Tarboton, Terrain analysis using digital elevation models (taudem) (2005).

URL http://hydrology.neng.usu.edu/taudem/

[48] S. Clode, F. Rottensteiner, P. Kootsookos, E. Zelniker, Detection and vectorization of roads from lidar data, Photogrammetric Engineering and Remote Sensing 73 (5) (2007) 517-535. doi:10.14358/PERS.73. 5.517 .

URL http://dx.doi.org/10.14358/PERS.73.5.517

[49] T. Krger, G. Meinel, Using Raster DTM for Dike Modelling, Lecture Notes in Geoinformation and Cartography, Springer Berlin Heidelberg, 2008, book section 6, pp. 101-113. doi:10.1007/978-3-540-72135-2_ 6.

URL http://dx.doi.org/10.1007/978-3-540-72135-2_6

[50] L. Siu, Processing of laser scanner data and automatic extraction of structure lines, in: International Archives of Photogrammetry and Remote Sensing, XXXIV, Part 2, Commission II, pp. 429-435.

[51] T. Lindeberg, Edge detection and ridge detection with automatic scale selection, in: Computer Vision and Pattern Recognition, 1996. Pro- 
ceedings CVPR '96, 1996 IEEE Computer Society Conference on, pp. 465-470. doi:10.1109/CVPR.1996.517113.

[52] T. M. Koller, G. Gerig, G. Szekely, D. Dettwiler, Multiscale detection of curvilinear structures in 2-d and 3-d image data, in: Computer Vision, 1995. Proceedings., Fifth International Conference on, pp. 864-869. doi:10.1109/ICCV.1995.466846.

[53] J. Westerink, R. Luettich, J. Muccino, Modeling tides in the western north atlantic using unstructured graded grids, Tellus 46A (1994) 178199. doi:10.1034/j.1600-0870.1994.00007.x.

[54] N. Booij, R. Ris, L. Holthuijsen, A third-generation wave model for coastal regions 1. model description and validation, Journal of Geophysical Research 104 (C4) (1999) 7649-7666. doi:10.1029/98JC02622.

[55] L. H. Holthuijsen, Waves in oceanic and coastal waters, Cambridge University Press, Cambridge, 2007, 2007274988 GBA633586 013431404 Leo H. Holthuijsen. ill., maps ; $26 \mathrm{~cm}$. Includes bibliographical references (p. 347-378) and index.

URL http://www.loc.gov/catdir/toc/fy0711/2007274988. htmlhttp://www.loc.gov/catdir/enhancements/fy0803/ 2007274988-b.htmlhttp://www.loc.gov/catdir/enhancements/ fy0803/2007274988-d.html

[56] J. Dietrich, M. Zijlema, J. Westerink, L. Holthuijsen, C. Dawson, R. Luettich, R. Jensen, J. Smith, G. Stelling, G. Stone, Modeling hurricane waves and storm surge using integrally-coupled, scalable computa- 
tions, Coastal Engineering 58 (2011) 45-65. doi:http://dx.doi.org/ $10.1016 / \mathrm{j}$.coastaleng.2010.08.001.

[57] M. Zijlema, Computation of wind-wave spectra in coastal waters with swan on unstructured grids, Coastal Engineering 57 (3) (2010) 267-277. doi:http://dx.doi.org/10.1016/j.coastaleng.2009.10.011. URL http://www.sciencedirect.com/science/article/pii/ S0378383909001616

[58] G. J. Komen, K. Hasselmann, K. Hasselmann, On the existence of a fully developed wind-sea spectrum, Journal of Physical Oceanography 14 (8) (1984) 1271-1285. doi:10.1175/1520-0485(1984)014<1271: OTEOAF>2.0. $\mathrm{CO} ; 2$.

URL http://dx.doi.org/10.1175/1520-0485(1984)014<1271: OTEOAF $>2.0 . \mathrm{CO} ; 2$

[59] L. Cavaleri, P. Rizzoli, Wind wave prediction in shallow water: Theory and applications, Journal of Geophysical Research: Oceans 86 (C11) (1981) 10961-10973. doi:10.1029/JC086iC11p10961.

URL http://dx.doi.org/10.1029/JC086iC11p10961

[60] W. Rogers, P. Hwang, D. Wang, Investigation of wave growth and decay in the swan model: Three regional-scale applications*, Journal of Physical Oceanography 33 (2) (2003) 366-389. doi:10.1175/1520-0485(2003)033<0366: IOWGAD>2.0.CD;2. URL http://dx.doi.org/10.1175/1520-0485(2003)033<0366: IOWGAD $>2.0 . \mathrm{CO} ; 2$ 
[61] J. A. Battjes, J. P. F. M. Janssen, Energy loss and set-up due to breaking of random waves, Coastal Engineering Proceedings; No 16 (1978): Proceedings of 16th Conference on Coastal Engineering, Hamburg, Germany, 1978.

URL http://journals.tdl.org/icce/index.php/icce/article/ view/3294

[62] O. Madsen, Y. Poon, H. Graber, Spectral Wave Attenuation By Bottom Friction: Theory.

[63] J. Dietrich, M. Zijlema, P. E. Allier, L. Holthuijsen, N. Booij, J. D. Meixner, J. K. Proft, C. N. Dawson, C. J. Bender, A. Naimaster, J. M. Smith, J. J. Westerink, Limiters for spectral propagation velocities in swan, Ocean Modelling 70 (2013) 85-102. doi:http://dx.doi.org/10.1016/j.ocemod.2012.11.005.

URL http://wWW.sciencedirect.com/science/article/pii/ S1463500312001655

[64] M. Hope, J. Westerink, A. Kennedy, P. Kerr, J. Dietrich, C. Dawson, C. Bender, J. Smith, R. Jensen, M. Zijlema, L. Holthuijsen, R. Luettich, M. Powell, V. Cardone, A. Cox, H. Pourtaheri, H. Roberts, J. Atkinson, S. Tanaka, H. Westerink, L. Westerink, Hindcast and validation of hurricane ike (2008) waves, forerunner, and storm surge, Journal of Geophysical Research: Oceansdoi:10.1002/jgrc.20314.

[65] M. Horritt, P. Bates, Predicting floodplain inundation: raster-based modelling versus the finite-element approach, Hydrological Processes 15 (2001) 825-842. doi:10.1002/hyp.188. 
[66] S. Medeiros, T. Ali, S. Hagen, Development of a seamless topographic/bathymetric digital terrain model for tampa bay, florida, Photogrammetric Engineering and Remote Sensing 77 (12) (2011) 12491256.

[67] M. Bilskie, Influence of topographic elevation error on modeled storm surge, Thesis (2012).

[68] D. Coggin, Lidar in coastal storm surge modeling: modeling linear raised features, Thesis (2008).

[69] H. J. Roberts, Grid generation methods for high resolution finite element models used for hurricane storm surge prediction, Thesis (2004).

[70] U. of Central Florida, Digital elevation model and finite element mesh development, Report, Northwest Florida Water Management District and the Federal Emergency Management Agency (Sept. 5, 2011 2011).

[71] A. Mukai, J. Westerink, R. Luettich, D. Mark, Eastcoast 2011: A tidal constituent database for the western north atlantic, gulf of mexico, and caribbean sea. tech. rep. erdc/chl tr-02-24,u.s. army corps of engineers, Report (2002).

[72] Aquaveo, Surface-water modeling system (2014). URL http://xmswiki.com/xms/SMS :SMS ,

[73] J. Atkinson, H. Roberts, S. Hagen, S. Zou, P. Bacopoulos, S. C. Medeiros, J. Weishampel, Z. Cobell, Deriving frictional parameters and performing historical validation for an adcirc storm surge model of the florida gulf coast, Florida Watershed Journal 4 (2) (2011) 22-27. 
[74] B. Buczkowski, J. Reid, J. Jenkins, C. Reid, S. Williams, J. Flocks, usseabed: Gulf of mexico and caribbean (puerto rico and u.s. virigin islands) offshore surficial sediment data release, Report, U.S. Geological Survey (2006).

[75] J. Dietrich, S. Tanaka, J. Westerink, C. Dawson, R. Luettich, M. Zijlema, L. Holthuijsen, J. Smith, L. Westerink, H. Westerink, Performance of the unstructured-mesh, swan+adcirc model in computing hurricane waves and surge, Journal of Scientific Computing 52 (2) (2012) 468-497.

[76] R. Martyr, J. Dietrich, J. Westerink, P. Kerr, C. Dawson, J. Smith, H. Pourtaheri, M. Powell, M. Van Ledden, S. Tanaka, H. J. Roberts, H. Westerink, L. Westerink, Simulating hurricane storm surge in the lower mississippi river under varying flow conditions, Journal of Hydraulic Engineering 139 (492) (2013) 492-501. doi:10.1061/(ASCE) HY.1943-7900.0000699.

[77] R. O. Reid, R. Whitaker, Wind-driven flow of water influence by a canopy, J. Waterw., Harbors, Coastal Engr. Div. 102 (1) (1976) 61-77.

[78] J. Dietrich, S. Bunya, J. J. Westerink, B. A. Ebersole, J. M. Smith, J. H. Atkinson, R. Jensen, D. T. Resio, R. A. Luettich, C. Dawson, V. J. Cardone, A. T. Cox, M. D. Powell, H. J. Westerink, H. J. Roberts, A high-resolution coupled riverine flow, tide, wind, wind wave, and storm surge model for southern louisiana and mississippi. part ii: Synoptic description and analysis of hurricanes katrina and rita, Monthly Weather 
Review 138 (2) (2010) 378-404. doi:10.1175/2009MWR2907.1.

URL http://dx.doi.org/10.1175/2009MWR2907.1

[79] M. Powell, S. Murillo, P. Dodge, E. Uhlhorn, J. Gamache, V. Cardone, A. Cox, S. Otero, N. Carrasco, A. B., R. St. Fluer, Reconstruction of hurricane katrinas wind elds for storm surge and wave hindcasting, Ocean Engineering 37 (2010) 26-26. doi:http://dx.doi.org/10. 1016/j.oceaneng.2009.08.014.

[80] B. A. Ebersole, J. J. Westerink, S. Bunya, J. C. Dietrich, M. A. Cialone, Development of storm surge which led to flooding in st. bernard polder during hurricane katrina, Ocean Engineering 37 (1) (2010) 91-103. doi:http://dx.doi.org/10.1016/j.oceaneng.2009.08.013.

URL http://www.sciencedirect.com/science/article/pii/ S0029801809002133

[81] G. Egbert, A. Bennett, M. Foreman, Topex/poseidon tides estimated using a global inverse model, Journal of Geophysical Research: Oceans 99 (C12) (1994) 24821-24852. doi:10.1029/94JC01894.

URL http://dx .doi .org/10.1029/94JC01894

[82] G. Egbert, S. Erofeeva, Efficient inverse modeling of barotropic ocean tides, Journal of Atmospheric and Oceanic Technology 19 (2) (2002) 183-204. doi:10.1175/1520-0426(2002)019<0183: EIMOBO>2.0.CO;2.

URL http://dx.doi.org/10.1175/1520-0426(2002)019<0183: EIMOBO $>2.0 . \mathrm{CO} ; 2$ 
[83] P. Bacopoulos, B. Dally, S. Hagen, A. Cox, Observations and simulation of winds, surge, and currents on florida's east coast during hurricane jeanne (2004), Coastal Engineering 60 (0) (2012) 84-94. doi:http://dx.doi.org/10.1016/j.coastaleng.2011.08.010. URL http://www.sciencedirect.com/science/article/pii/ S0378383911001608

[84] J. Hanson, B. Tracy, H. Tolman, R. Scott, Pacific hindcast performance of three numerical wave models, Journal of Atmospheric and Oceanic Technology 26 (8) (2009) 1614-1633. doi:10.1175/2009JTECH0650.1. URL http://dx.doi.org/10.1175/2009JTECH0650.1

[85] D. Dietsche, S. C. Hagen, P. Bacopoulos, Storm surge simulations for hurricane hugo (1989): On the significance of inundation areas, Journal of Waterway, Port, Coastal, and Ocean Engineering 133 (3) (2007) 183191.

[86] G. Gibson, An analysis of shoreline change at little lagoon, alabama, Thesis (2006).

[87] S. Medeiros, S. Hagen, J. Weishampel, Comparison of floodplain surface roughness parameters derived from land cover data and field measurements, Journal of Hydrology 452453 (0) (2012) 139-149. doi:http://dx.doi.org/10.1016/j.jhydrol.2012.05.043. URL http://www.sciencedirect.com/science/article/pii/ S0022169412004325 


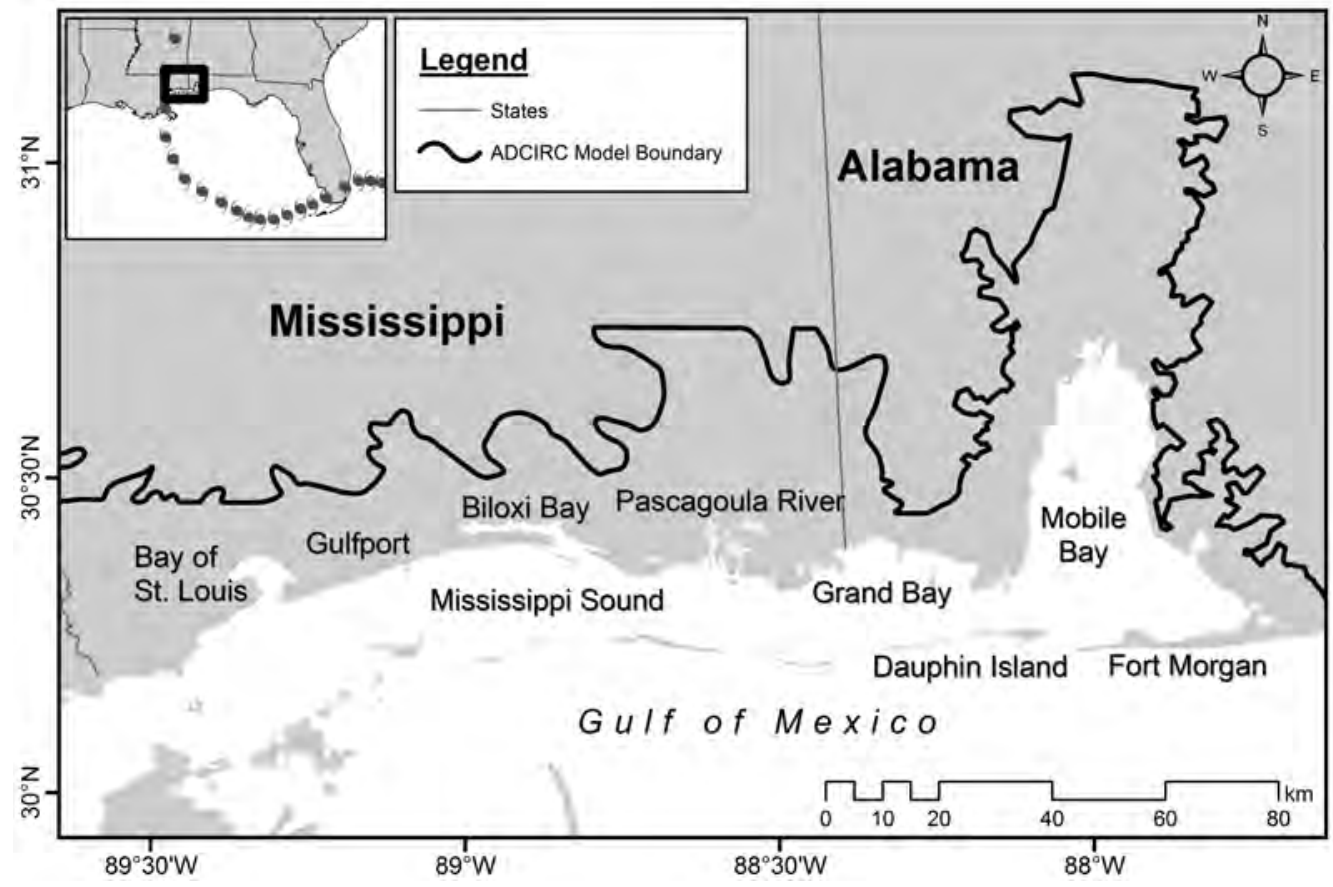

Figure 1: Location map of coastal Mississippi and Alabama with coastal features labeled and the track of Hurricane Katrina. The ADCIRC model boundary is in black. 


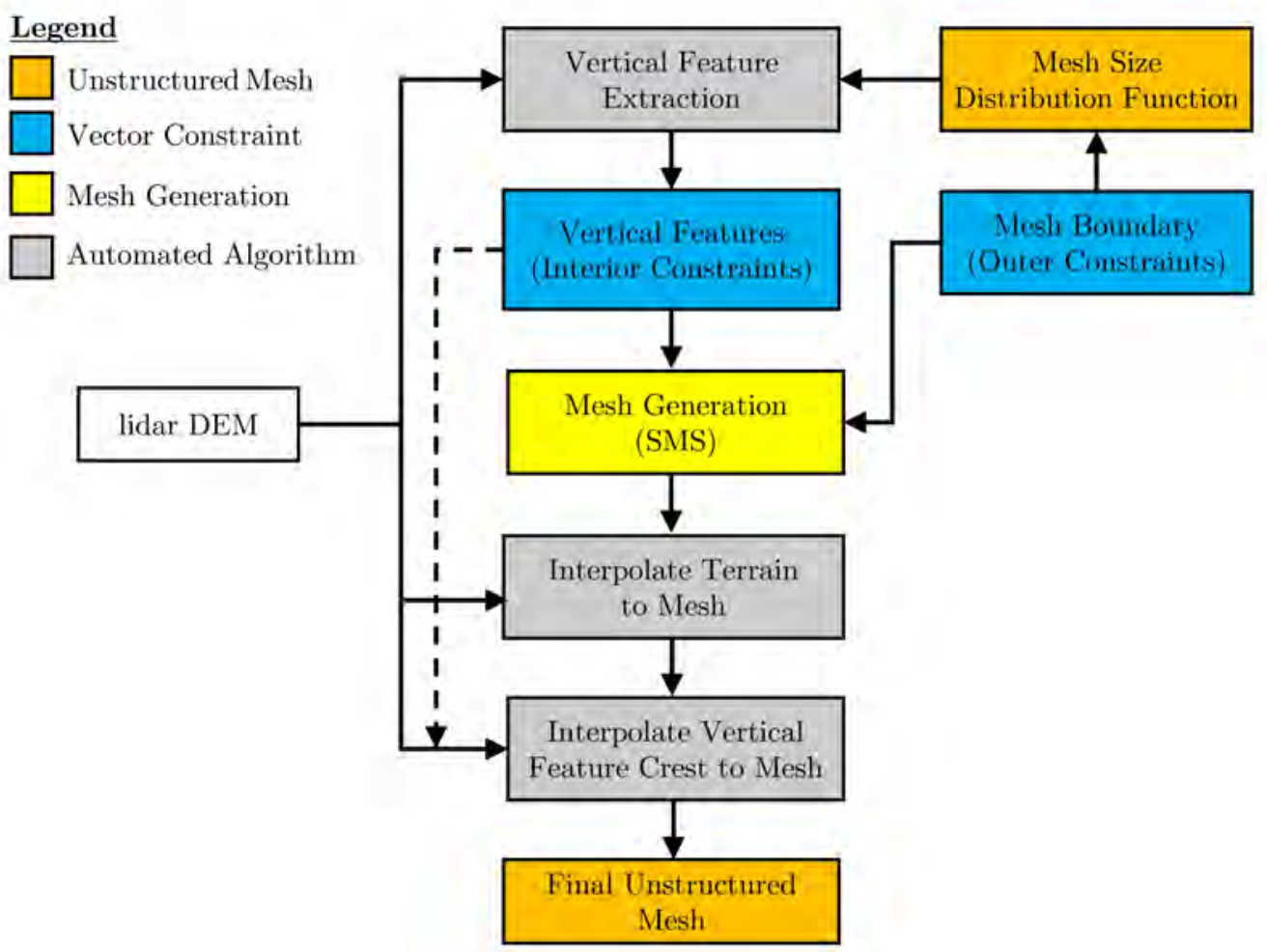

Figure 2: Flow chart outlining the mesh generation procedure. The process begins with the lidar DEM and mesh boundary. 


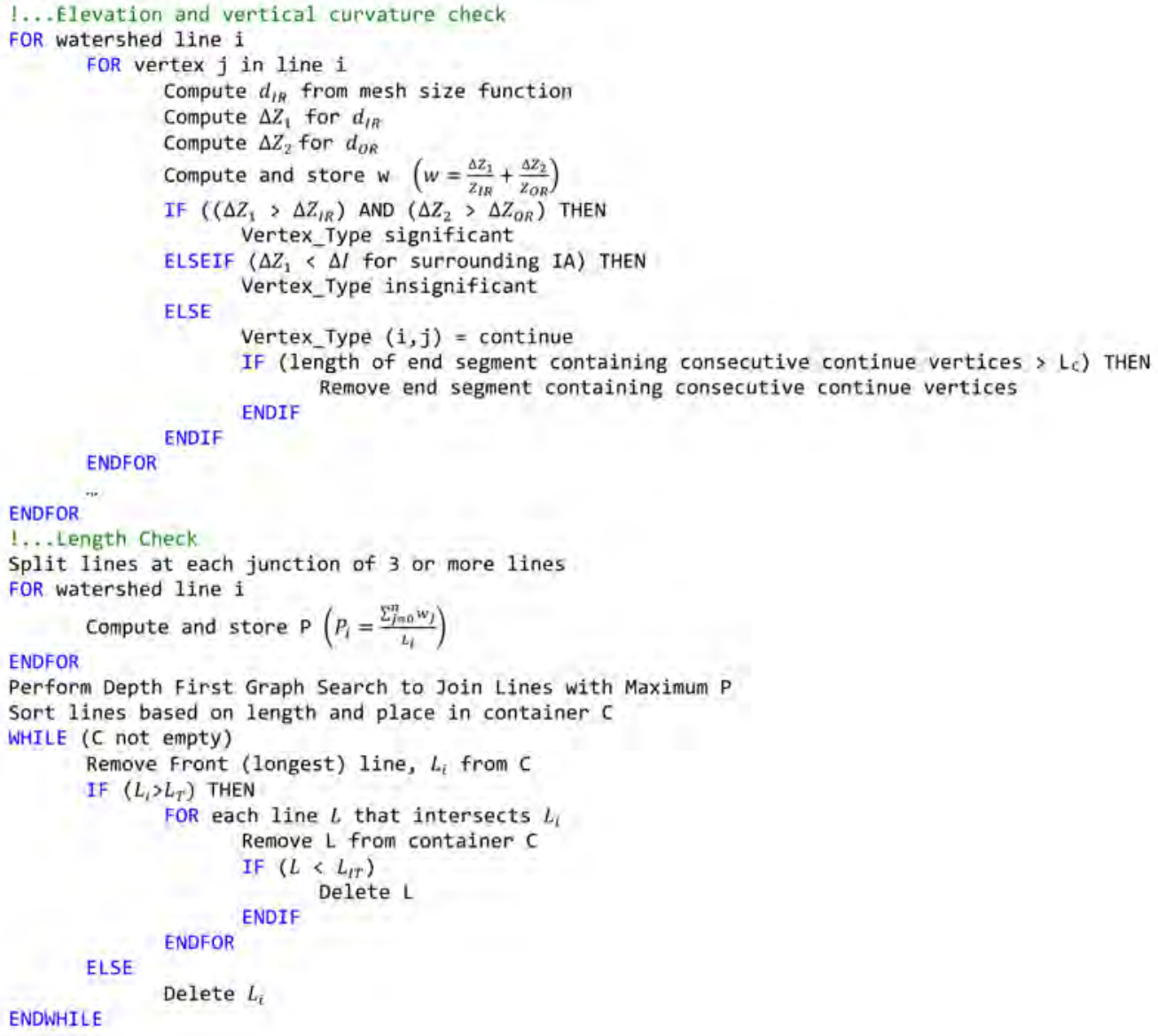

Figure 3: Pseudo-code for the main vertical feature extraction algorithm. 

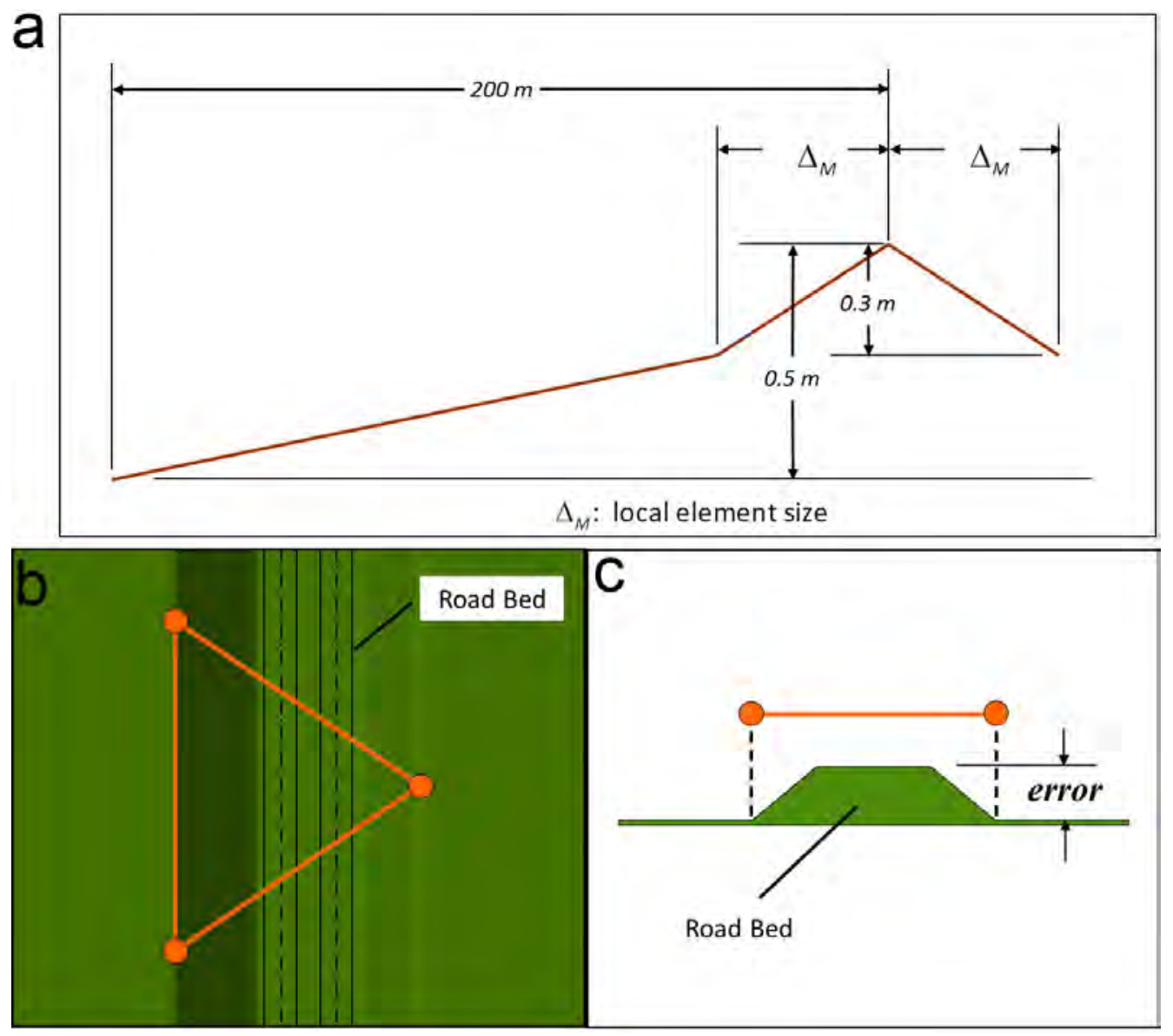

Figure 4: a) Elevation and perpendicular distance requirements for vertical feature extractions. b) Elevation error due to triangular element placement.c) Planar view showing triangular element in worst possible position relative to a road bed. 


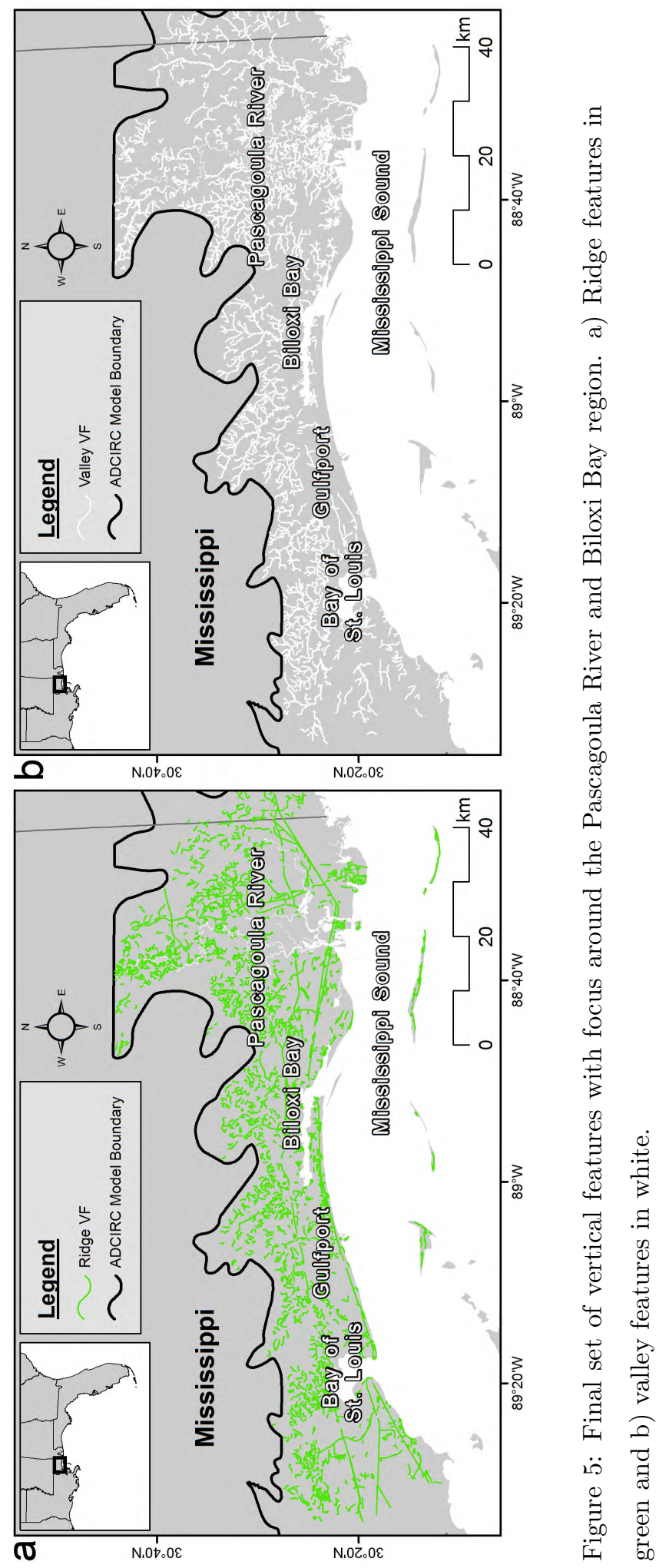




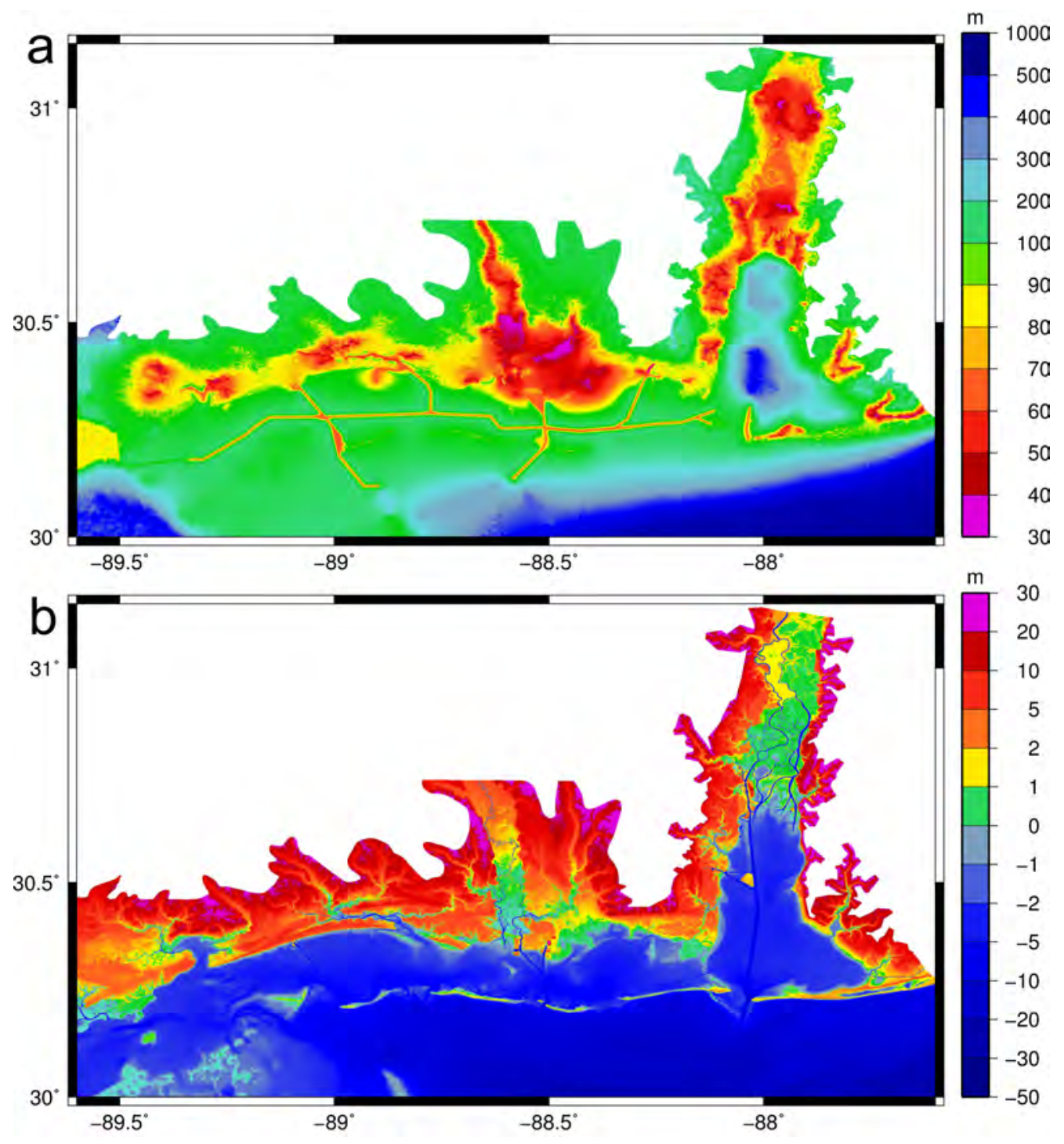

Figure 6: ADCIRC a) mesh resolution (m) and b) model topography and bathymetry of the $M S A L$ mesh in Mississippi and Alabama. 

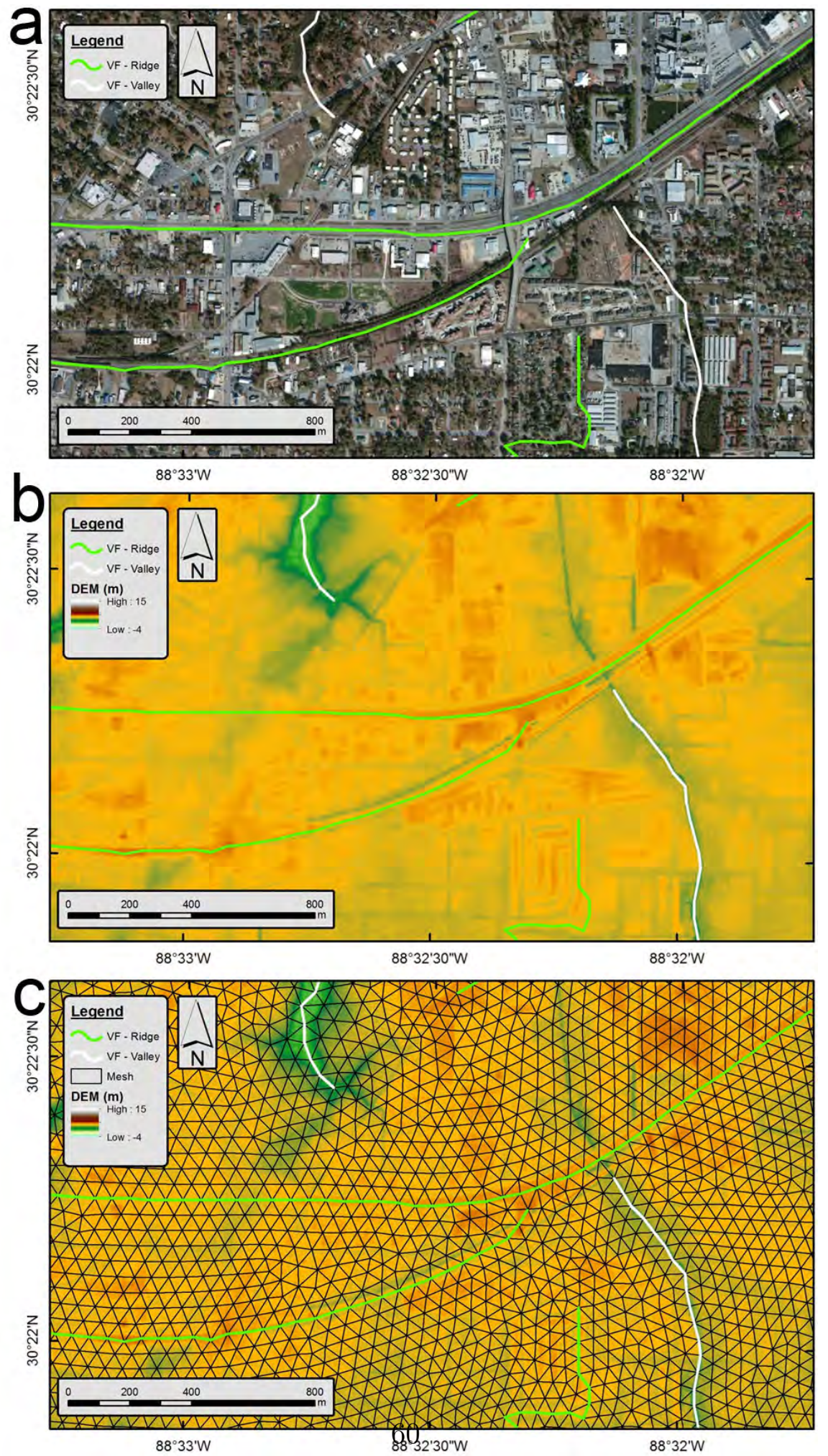

Figure 7: a) Aerial imagery and derived vertical features (green $=$ ridge and white $=$ valley); b) $5 \mathrm{~m}$ DEM and vertical features; c) $5 \mathrm{~m}$ DEM, vertical features, and unstructured finite element mesh with element edges aligned to the vertical feature lines (approximate element resolution is $60-80 \mathrm{~m}$ ). 


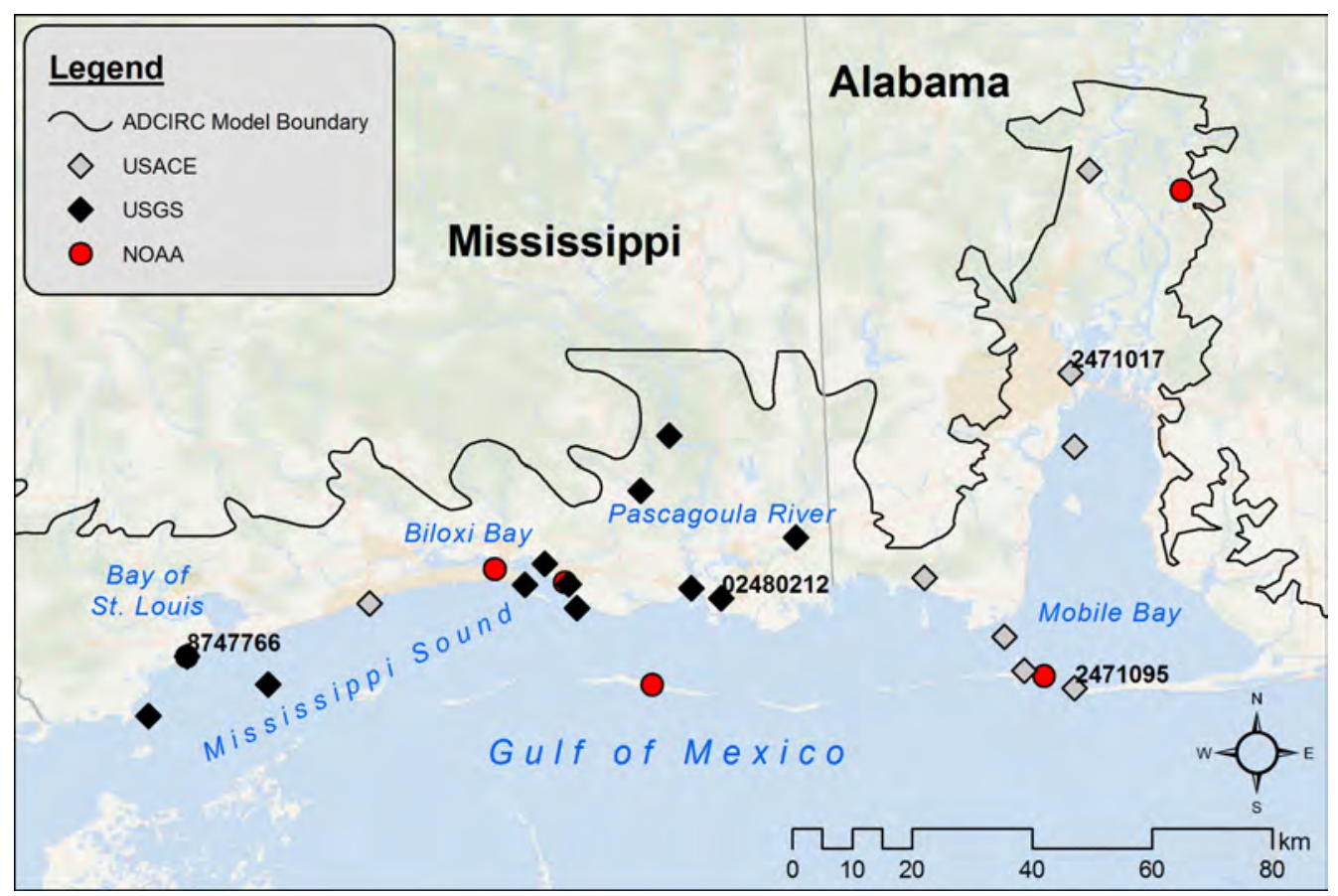

Figure 8: Location of the USACE storm tide elevation sensors (gray), USGS streamgages (black), and NOAA tide gages (red) with measured Hurricane Katrina time-series water levels along the Mississippi-Alabama coast. Hydrographs are shown of stations with labels. The ADCIRC model boundary is in black. 

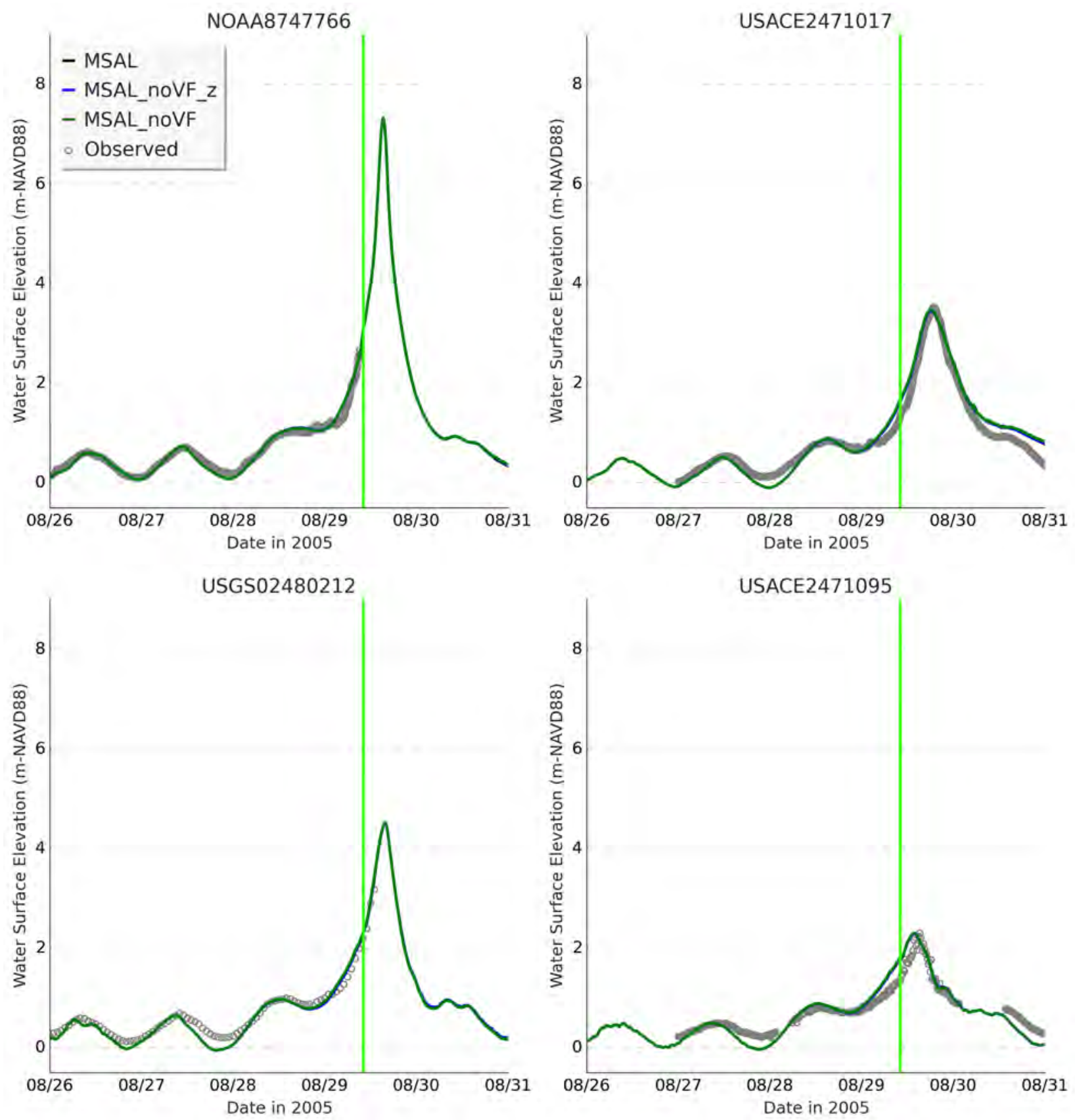

Figure 9: Water surface elevation (m, NAVD88) time-series (UTC) at a selected 4 gage stations during Hurricane Katrina. The measured data are the gray circles, $M S A L$ result is shown as the black line, $M S A L_{-} n o V F_{-} z$ is in blue, and $M S A L_{-} n o V F_{-} z$ in dark green. The vertical neon green line is the landfall6date and time. The three model simulation lines lie on top of one another. 

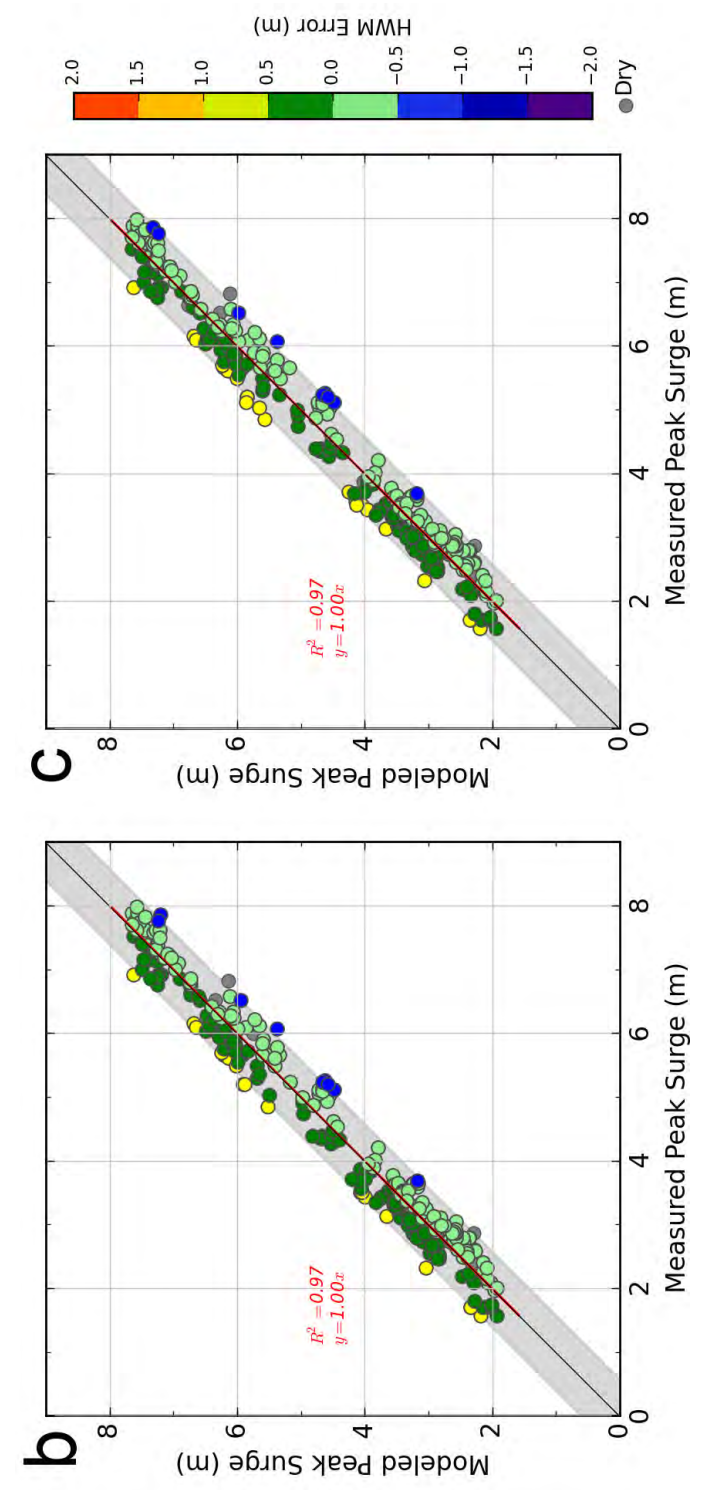

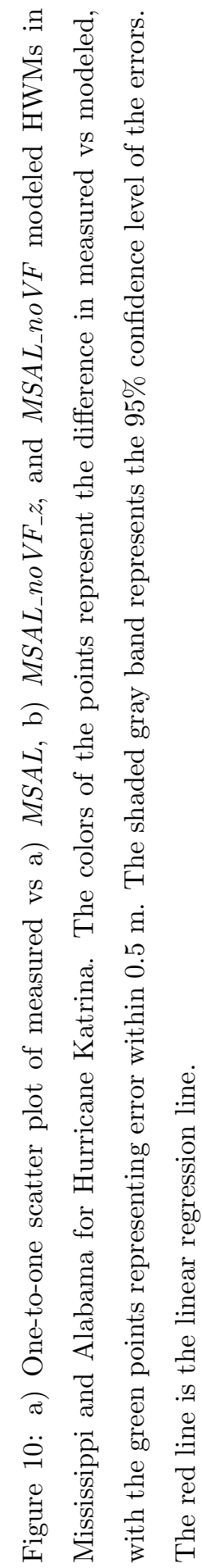

$\sigma$

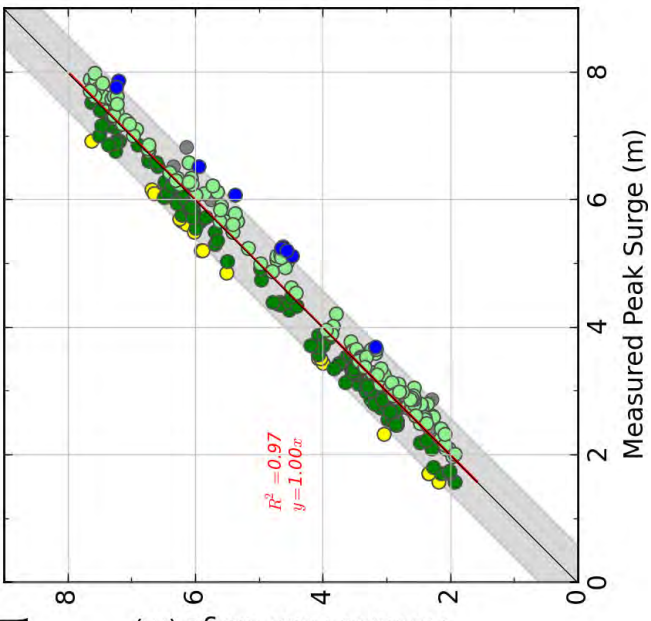

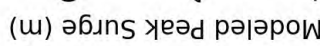




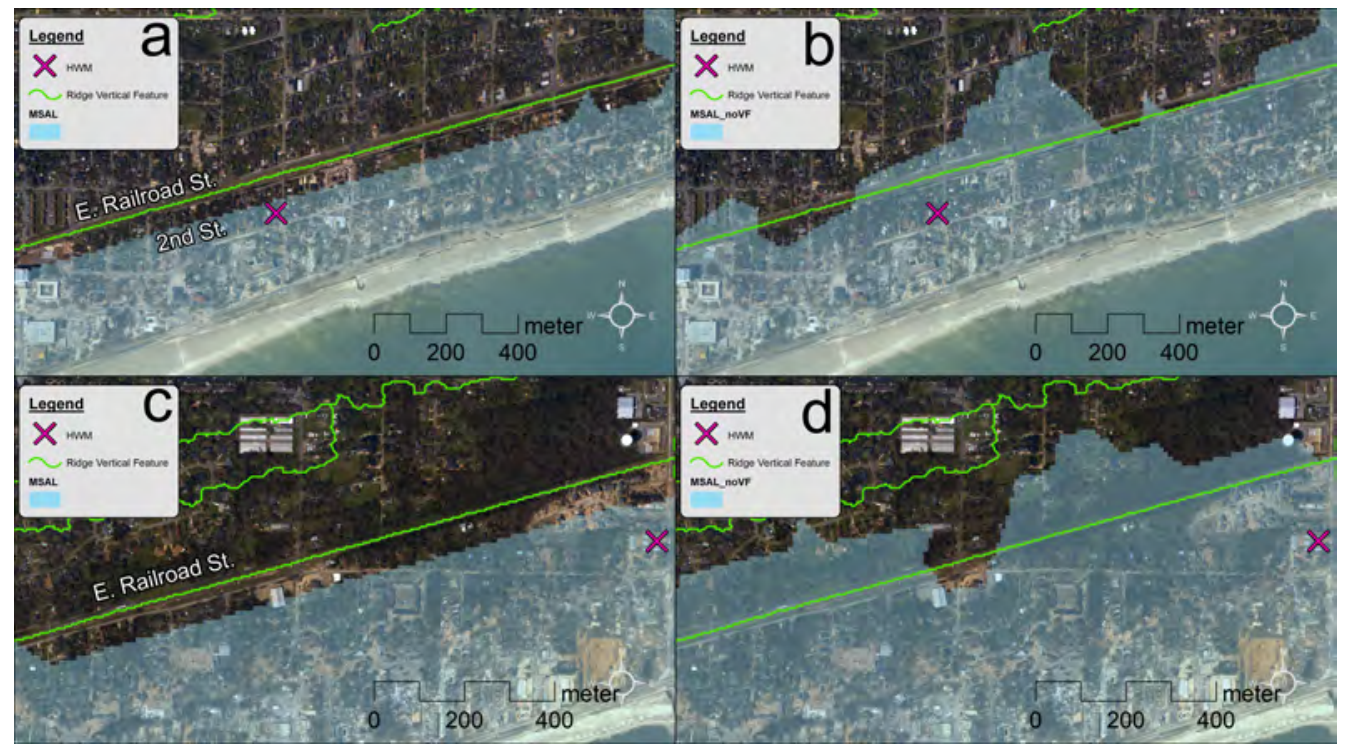

Figure 11: a) $M S A L$ and b) $M S A L \_n o V F$ inundation extent on top of the NOAA postKatrina aerial imagery just west of Gulfport Harbor. The HWM (purple cross) value and error at this location (a-b) is $7.59 \mathrm{~m}$ and $-0.25 \mathrm{~m}$. c) $M S A L$ and d) $M S A L_{-} n o V F$ inundation extent on top of the NOAA post-Katrina aerial imagery $5 \mathrm{~km}$ west of Gulfport Harbor. The HWM (purple cross) value and error at this location (c-d) is $7.25 \mathrm{~m}$ and $-0.09 \mathrm{~m}$. The green lines are vertical feature ridge lines. Model resolution in this region is $60-100 \mathrm{~m}$. 


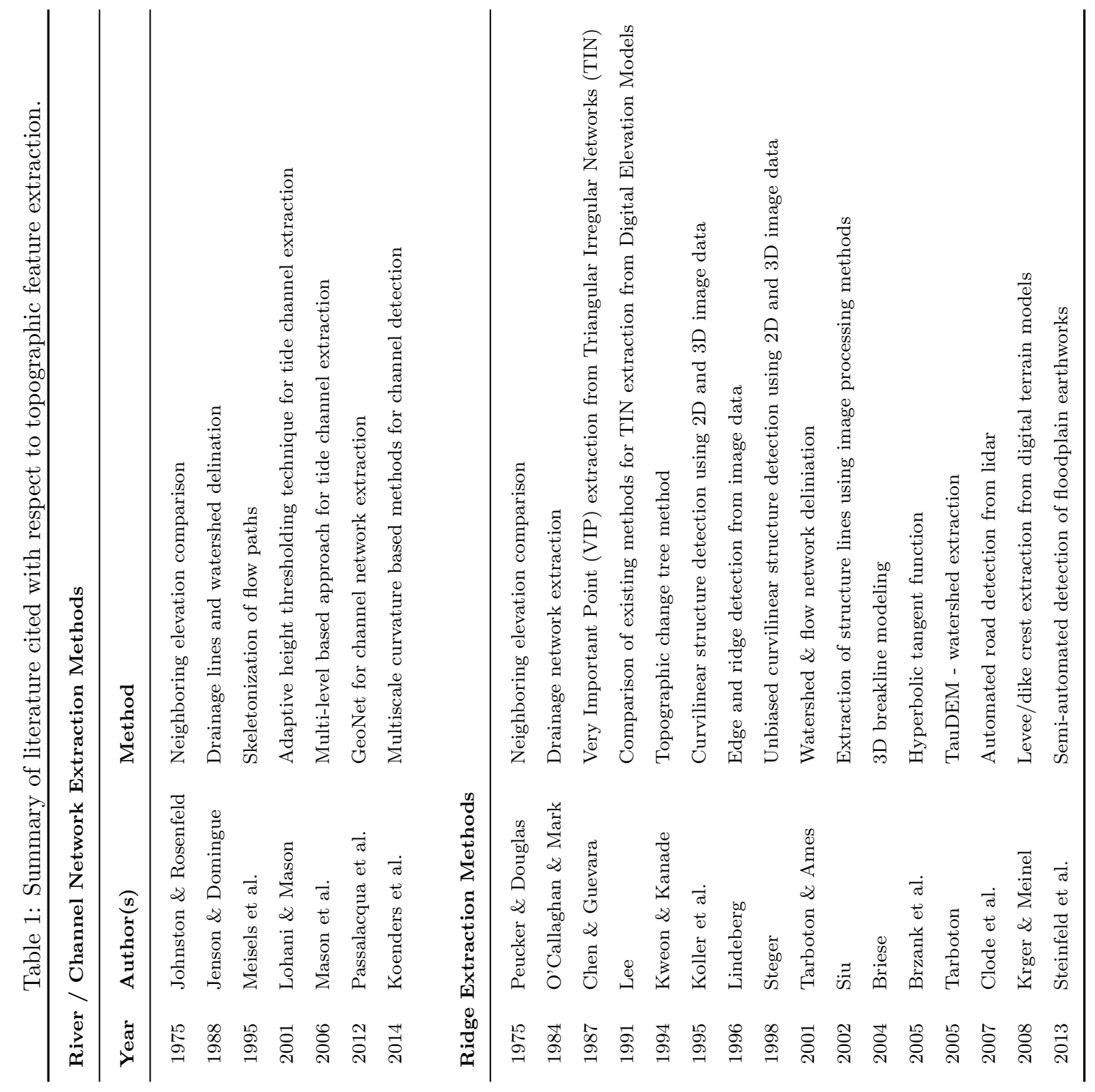


Table 2: List of parameters and respective values used in the vertical feature extraction algorithm

Variable Value Note

\section{Elevation Parameters}

$\begin{array}{ccl}d_{I R} & \frac{\text { les }}{2} & \text { Inner Range Distance } \\ \text { les } & - & \text { Local Element Size } \\ d_{O R} & 200 \mathrm{~m} & \text { Outer Range Distance } \\ \Delta Z_{I R} & 0.3 \mathrm{~m} & \text { Inner Range Outer Distance } \\ \Delta Z_{O R} & 0.5 \mathrm{~m} & \text { Outer Range Outer Distance } \\ \Delta_{I} & 0.1 \mathrm{~m} & \text { Insignificant Elevation Difference } \\ I A & 2,000 \mathrm{~m}^{2} & \text { Insignificant Area } \\ L_{C} & 200 \mathrm{~m}^{2} & \text { Continue Length } \\ r_{s} & 0.35 & \text { Significant line ratio }\end{array}$

\section{Vertical Curvature}

$\Delta_{V C} \quad 0.3 m^{2} \quad$ Vertical Curvature Elevation Difference

\section{Length Parameters}

$\begin{array}{ccl}P & - & \text { Priority Weighting Factor } \\ L_{T} & 1,000 \mathrm{~m} & \text { Trunk Length } \\ L_{I T} & 500 \mathrm{~m} & \text { Intersect Trunk Length }\end{array}$


Table 3: Mannings n, surface canopy and surface directional effective roughness length (Z0) values for CCAP Land Use Land Cover classifications.

\begin{tabular}{|c|c|c|c|c|}
\hline CCAP Class & Description & Manning's n & Canopy Value & $Z_{0}$ \\
\hline 2 & High Intensity Developed & 0.12 & 1 & 0.5 \\
\hline 3 & Medium Intensity Developed & 0.12 & 1 & 0.39 \\
\hline 4 & Low Intensity Developed & 0.12 & 1 & 0.5 \\
\hline 5 & Developed Open Space & 0.035 & 1 & 0.33 \\
\hline 6 & Cultivated Land & 0.1 & 1 & 0.06 \\
\hline 7 & Pasture/Hay & 0.05 & 1 & 0.06 \\
\hline 8 & Grassland & 0.035 & 1 & 0.04 \\
\hline 9 & Deciduous Forest & 0.16 & 0 & 0.65 \\
\hline 10 & Evergreen Forest & 0.18 & 0 & 0.72 \\
\hline 11 & Mixed Forest & 0.17 & 0 & 0.71 \\
\hline 12 & Scrub/Shrub & 0.08 & 1 & 0.12 \\
\hline 13 & Palustrine Forested Wetland & 0.15 & 0 & 0.55 \\
\hline 14 & Palustrine Scrub/Shrub Wetland & 0.075 & 0 & 0.11 \\
\hline 15 & Palustrine Emergent Wetland & 0.06 & 1 & 0.11 \\
\hline 16 & Estuarine Forested Wetland & 0.15 & 0 & 0.55 \\
\hline 17 & Estuarine Scrub/Schrub Wetland & 0.07 & 1 & 0.12 \\
\hline 18 & Estuarine Emergent Wetland & 0.05 & 1 & 0.11 \\
\hline 19 & Unconsolidated Shore & 0.03 & 1 & 0.09 \\
\hline 20 & Bare Land & 0.03 & 1 & 0.09 \\
\hline 21 & Open Water & 0.025 & 1 & 0 \\
\hline 22 & Palustrine Aquatic Bed & 0.035 & 1 & 0.04 \\
\hline 23 & Estuarine Aquatic Bed & 0.03 & 1 & 0.04 \\
\hline
\end{tabular}


Table 4: Error summary for $M S A L$ computed water levels for each of the measured water level datasets.

\begin{tabular}{cccc}
\hline Data Agency & No. Stations & SI & Bias \\
\hline NOAA & 7 & 0.12 & -0.01 \\
USACE & 8 & 0.25 & -0.01 \\
USGS & 7 & 0.26 & -0.05 \\
All & 22 & 0.21 & -0.02 \\
\hline
\end{tabular}




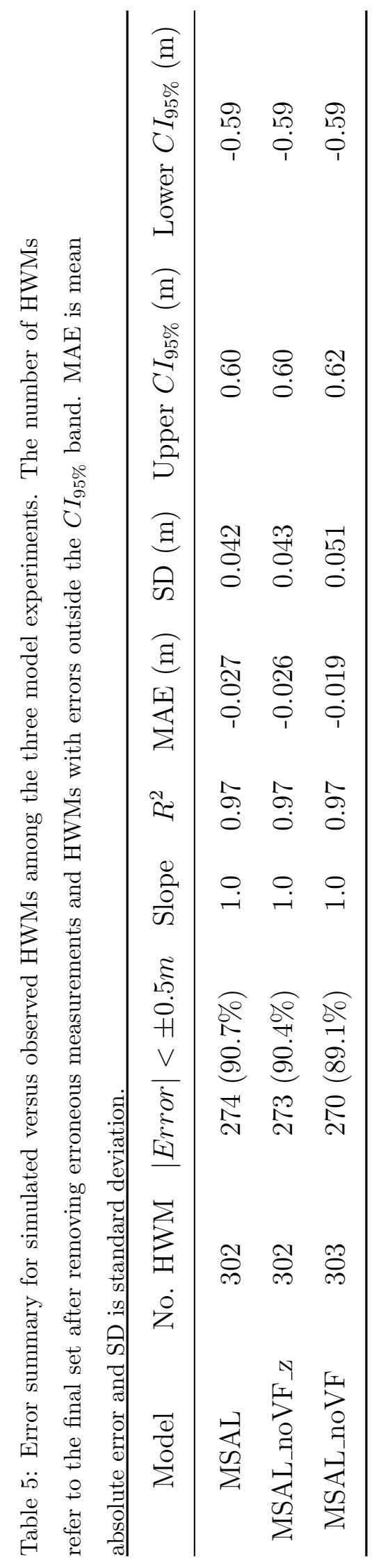

